This document is confidential and is proprietary to the American Chemical Society and its authors. Do not copy or disclose without written permission. If you have received this item in error, notify the sender and delete all copies.

\title{
Time-Resolved Femtosecond Stimulated Raman Spectra and DFT Anharmonic Vibrational Analysis of an Electronically Excited Rhenium Photosensitizer
}

\begin{tabular}{|r|l|}
\hline Journal: & The Journal of Physical Chemistry \\
\hline Manuscript ID & jp-2019-10840r.R2 \\
\hline Manuscript Type: & Article \\
\hline Date Submitted by the & $\mathrm{n} / \mathrm{a}$ \\
\hline Complete List of Authors: & $\begin{array}{l}\text { Pizl, Martin; Ustav fyzikalni chemie J Heyrovskeho Akademie Ved Ceske } \\
\text { Republiky, } \\
\text { Picchiotti, Alessandra; Institute of Physics Czech Academy of Sciences } \\
\text { Rebarz, Mateusz; Institute of Physics Czech Academy of Sciences } \\
\text { Lenngren, Nils; Institute of Physics Czech Academy of Sciences } \\
\text { Yingliang, Liu; Institute of Biotechnology Czech Academy of Sciences } \\
\text { Zalis, Stanislav; Ustav fyzikalni chemie J Heyrovskeho Akademie Ved } \\
\text { Ceske Republiky, } \\
\text { Kloz, Miroslav; Institute of Physics Czech Academy of Sciences } \\
\text { Vlcek, Antonin; Queen Mary University of London, SBCS }\end{array}$ \\
\hline
\end{tabular}

\section{SCHOLARONE ${ }^{\text {th }}$ Manuscripts}




\title{
Time-Resolved Femtosecond Stimulated Raman Spectra and DFT Anharmonic Vibrational Analysis of an Electronically Excited Rhenium Photosensitizer
}

\author{
Martin Pižl, ${ }^{\mathrm{a}, \mathrm{b}}$ Alessandra Picchiotti, ${ }^{\mathrm{c}}$ Mateusz Rebarz, ${ }^{\mathrm{c}}$ Nils Lenngren, ${ }^{\mathrm{c}}$ Liu Yingliang, ${ }^{\mathrm{d}}$ Stanislav \\ Zálišs, ${ }^{a}$ Miroslav Kloz, ${ }^{*, c}$ Antonín Vlček*,a,e \\ a J. Heyrovský Institute of Physical Chemistry, Czech Academy of Sciences, Dolejškova 3, \\ 18223 Prague, Czech Republic \\ b Department of Inorganic Chemistry, University of Chemistry and Technology, Prague, \\ Technická 5, CZ-166 28 Prague, Czech Republic \\ c ELI Beamlines, Institute of Physics, Czech Academy of Sciences, Na Slovance 1999/2, 18200 \\ Prague, Czech Republic \\ d Institute of Biotechnology, Czech Academy of Sciences, Průmyslová 595 \\ 25250 Vestec, Czech Republic \\ e Queen Mary University of London, School of Biological and Chemical Sciences, Mile End Road, \\ London E1 4NS, United Kingdom
}

\begin{abstract}
Time-resolved femtosecond stimulated Raman spectra (FSRS) of a prototypical organometallic photosensitizer/photocatalyst $\operatorname{ReCl}(\mathrm{CO})_{3}(2,2$ '-bipyridine) were measured in a broad spectral range $\sim 40-2000(4000) \mathrm{cm}^{-1}$ at time delays from $40 \mathrm{fs}$ to $4 \mathrm{~ns}$ after $400 \mathrm{~nm}$ excitation of the lowest allowed electronic transition. Theoretical ground- and excited-state Raman spectra were obtained by anharmonic vibrational analysis using second-order vibrational perturbation theory on vibrations calculated by harmonic approximation at DFT-optimized structures. A good match with anharmonically calculated vibrational frequencies allowed for assigning experimental Raman features to particular vibrations. Observed frequency shifts upon excitation $(v(\mathrm{ReCl})$ and $v(\mathrm{CC}$ inter-ring) vibrations upwards; $v(\mathrm{CC}, \mathrm{CN})$ and $v(\mathrm{Re}-\mathrm{C})$ downwards) are consistent with the bonding/antibonding characters of HOMO and LUMO involved in the excitation and support the delocalized formulation of the lowest triplet state as $\mathrm{ReCl}(\mathrm{CO})_{3} \rightarrow$ bpy charge-transfer. FSRS
\end{abstract}


spectra show a mode-specific temporal evolution, providing insight into the intersystem crossing (ISC) mechanism and subsequent relaxation. Most of the Raman features are present at $40 \mathrm{fs}$ and exhibit small shifts and intensity changes with time. The $1450-1600 \mathrm{~cm}^{-1}$ group of bands due to $\mathrm{CC}, \mathrm{CN}$, and $\mathrm{CC}$ (inter-ring) stretching vibrations undergoes extensive restructuring between 40 and $\sim 150 \mathrm{fs}$, followed by frequency upshifts and a biexponential $(0.38,21 \mathrm{ps})$ area growth, indicating progressing charge separation in the course of the formation and relaxation of the lowest triplet state. Early (40-150 fs) restructuring was also observed in the lowfrequency range for $v($ Re-Cl) and $\delta($ Re-C-O) vibrations that are presumably activated by ISC. FSRS experimental innovations employed to measure low- and high- energy Raman features simultaneously are described and discussed in detail.

\section{- INTRODUCTION}

Time-resolved vibrational spectroscopic methods are excellent techniques to characterize electronically excited states, as well as products and intermediates of photochemical reactions. Time-resolved infrared $(T R I R)^{1,2}$ and $\operatorname{Raman}^{3,4,5,6,7}$ experiments provide structural and dynamical information through temporal evolution of spectral patterns, band shapes, and intensities. Comparing ground- and excited-state spectra allow us to understand structural changes and electron-density redistribution upon excitation. The time evolution of IR and Raman band positions and shapes report on relaxation processes while time-dependent band intensities (areas) shed light on excited-state decay and reactivity.

To extract maximum information from vibrational spectroscopic experiments, we need to measure over spectral and temporal ranges as broad as possible and the spectral features 
must be correctly assigned to corresponding vibrations. TRIR spectra are usually reported at frequencies higher than $\sim 1100 \mathrm{~cm}^{-1}$, often focusing on strong IR chromophores (inorganic carbonyls, cyanides, isocyanides, $\mathrm{SCN}-,-\mathrm{C} \equiv \mathrm{C}-$, etc.) that give rise to well-separated bands between 1800 and $2300 \mathrm{~cm}^{-1}$. Important results were also obtained in the region aromatic CC vibrations ${ }^{2}$ which, however, is more crowded, complicating the spectral assignment. Timeresolved femtosecond stimulated Raman spectroscopy (TR-FSRS) is complementary to TRIR and could be more selective for particular chromophores owing to (pre)resonance enhancement. Although the low-frequency range $\left(\sim 40-800 \mathrm{~cm}^{-1}\right)$ could be very informative, most FSRS studies report spectra above $\sim 800 \mathrm{~cm}^{-1}$, presumably due to technical difficulties in generating the probing white-light continuum close to the Raman pump wavelength.

Assignment of intense high-frequency vibrational bands can be done empirically in combination with symmetry arguments, but this approach often fails in fingerprint and, especially, low-frequency regions. Moreover, molecular vibrations are substantially more delocalized over different bonds and more strongly coupled than can be captured by empirical assignments. Contemporary DFT software packages routinely perform vibrational analysis by treating molecular vibrations as harmonic oscillators. Such calculations predict main spectral features and corresponding normal coordinates. However, the quantitative match between calculated and experimental frequencies often is not satisfactory, with accuracy decreasing at lower frequencies. Multiplicative correction factors, which depend on the basis set and the functional, are often used. The harmonic approximation misses overtones and combination bands that contribute to spectral patterns and affect band shapes. It predicts equal energy spacing between vibrational levels and neglects many vibrational couplings, and is thus 
unsuitable for interpretation of diagonal and off-diagonal anharmonicities and cross-peaks in 2dimensional IR spectra. ${ }^{8,9}$ Anharmonic vibrational calculations overcome these problems. Computational techniques based on second-order vibrational perturbation theory (VPT2) suitable for medium-size molecular systems have been implemented only recently and were found to considerably improve the match between theory and experiment and to enable assignments of elusive spectral features. ${ }^{10,11,12,13,14}$

We report time-resolved FSRS of ground- and lowest electronic excited states of fac$\operatorname{ReCl}(\mathrm{CO})_{3}(\mathrm{bpy})$ (bpy = 2,2'-bipyridine) measured across the full chemically relevant range (100$\left.4000 \mathrm{~cm}^{-1}\right)$, together with their anharmonic DFT assignments. $\operatorname{ReCl}(\mathrm{CO})_{3}(\mathrm{bpy})$ is a prototypical member of the rhenium-carbonyl-polypyridine family of versatile redox photosensitizers/photooxidants and luminescent imaging agents. ${ }^{15,16,17}$ It also is a well-known photo- and electro-catalyst of $\mathrm{CO}_{2}$ reduction. ${ }^{18,19,20,21}$ In most cases, TRIR is the technique of choice to study excited states of $\operatorname{ReCl}(\mathrm{CO})_{3}($ bpy $)$ and its congeners, owing to the presence of strong $v(C \equiv O)$ IR bands that are highly sensitive to the electron density distribution. $1,15,22,23,24,25$ In particular, the lowest excited state of $\mathrm{ReCl}(\mathrm{CO})_{3}($ bpy) was unambiguously characterized by $v(\mathrm{CO})$ TRIR spectra as predominantly metal-to-ligand charge transfer (MLCT) and approximately formulated as $\mathrm{Re}^{\|} \mathrm{Cl}(\mathrm{CO})_{3}\left(\mathrm{bpy}^{\bullet-}\right) \cdot{ }^{14,15,22,23,26}$ High-frequency IR features of both the electronic ground and excited states were assigned by anharmonic DFT calculations, which also identified bpy-based combination bands occurring unexpectedly close to $v(\mathrm{CO})$ features. ${ }^{14}$ Far less is known about the behavior of bpy-localized and low-frequency skeletal modes whose IR signatures are much weaker or wholly unavailable. Some of the excited-state bpy-localized vibrational features were observed in the static transient resonance Raman $\left(T R^{2}\right)$ spectrum of 
$\operatorname{ReCl}(\mathrm{CO})_{3}($ bpy $)$ measured with a $364 \mathrm{~nm}$ pump, ${ }^{27}$ while picosecond temporal evolution of several bpy-localized Raman bands of $\operatorname{ReCl}(\mathrm{CO})_{3}(\mathrm{bpy})$ and $\left[\operatorname{Re}(4-\mathrm{Et}-\text { pyridine })(\mathrm{CO})_{3}(\mathrm{bpy})\right]^{+}$was followed by time-resolved resonance Raman spectra $\left(T R^{3}\right)$ probed at $400 \mathrm{~nm} .^{26}$ Both experiments took advantage of (pre)resonance enhancement due to a strong $\pi \pi^{*}\left(\mathrm{bpy}^{\bullet-}\right)$ electronic transition at $373 \mathrm{~nm}$

This study demonstrates the power of combining TR-FSRS experiments in the range of skeletal and ligand-localized vibrations with DFT calculations and 2nd order perturbational anharmonic DFT vibrational analysis in characterizing structural and electronic changes upon excitation and excited-state evolution on the femto-picosecond timescale.

\section{- EXPERIMENTAL AND COMPUTATIONAL TECHNIQUES}

Materials

$\operatorname{ReCl}(\mathrm{CO})_{3}(\mathrm{bpy})$ was prepared according to a literature procedure ${ }^{28}$ by a $\sim 3 \mathrm{hr}$ reflux of $\operatorname{Re}(\mathrm{CO})_{5} \mathrm{Cl}$ and 2,2'-bpy in a 1:1.1 molar ratio (both Sigma-Aldrich) in degassed toluene followed by extensive washing of the precipitated product with toluene and diethylether. Purity was checked by IR and NMR. Nearly saturated solutions in $\mathrm{CH}_{3} \mathrm{CN}$ and $\mathrm{CD}_{3} \mathrm{CN}$ (Sigma-Aldrich, spectroscopic quality) were used under air atmosphere.

\section{Femtosecond Stimulated Raman Spectroscopy}

The FSRS setup at ELI-Beamlines (Inst. of Physics, Prague) is pumped by a commercial 1 $\mathrm{kHz}$ titanium sapphire femtosecond amplifier system Femtopower (Spectra-Physics) generating $20 \mathrm{fs}$ pulses centered at $800 \mathrm{~nm}$. The beam is split by dielectric beam splitters into three 
synchronized beam paths: $1 \mathrm{~mJ}$ driving the "actinic pump" generation, $1.5 \mathrm{~mJ}$ driving the "Raman pump" generation, and $200 \mu \mathrm{J}$ driving the "probe" generation. Actinic pulses are converted to $400 \mathrm{~nm}$ by second-harmonic generation in a BBO crystal and passed through an optical delay line that allows setting their timing relative to probe and Raman pump pulses with a sub-10 fs precision. Actinic pulses are attenuated to an average energy of $2 \mu \mathrm{J}$ at the sample by a gradient neutral-density filter. Raman pump pulses are generated by sending $800 \mathrm{~nm}, \sim 20$ fs driving pulses through a home-built $4 \mathrm{f}$ pulse shaper that selects a spectrally narrow interval, effectively generating pulses approximately $1 \mathrm{~nm}$ broad, $2 \mathrm{ps}$ long, and with $\sim 3 \mu \mathrm{J}$ energy, whose center wavelength is tunable within the $\sim 1000 \mathrm{~cm}^{-1}$ width of the generating $800 \mathrm{~nm}$ pulse. A chopper whee ${ }^{29}$ installed in the Fourier plane of the pulse shaper consecutively generated 96 different wavelengths of the Raman pump pulse, each shifted by approximately $10 \mathrm{~cm}^{-1}$ from the previous one in the $765-835 \mathrm{~nm}$ interval. Pulses were adjusted to an average energy of $3 \mu$ at the sample by a linear-gradient neutral density filter. The probe is generated by a two-stage process. A home-built supercontinuum-seeded NOPA converts $800-\mathrm{nm}$ pulses into $1400-\mathrm{nm}$ pulses that are subsequently focused into a 2-mm sapphire plate, generating the probe supercontinuum, which is separated from the $1400 \mathrm{~nm}$ driving pulses by a dichroic beamsplitter. The probe supercontinuum spectrum spans from 350 to $1200 \mathrm{~nm}$ and is conveniently flat around the $800 \mathrm{~nm}$ Raman pump wavelength. The relative polarization of Raman pump and probe beams were set parallel by a half-wave-plate in the Raman pump path, while polarization of the actinic pulse was set to the magic angle $\left(54.7^{\circ}\right)$ relative to the probe using a half-wave-plate, in order to suppress possible polarization-related effects. The relative 
timing of Raman pump and probe pulses is adjusted to provide maximal FSRS signal, which is known to occur close to, but not exactly at, the perfect temporal overlap. ${ }^{30}$

After the sample, the probe is split into two copies that are spectrally imaged and analyzed by two respective imaging spectrographs (Acton Princeton Instruments) operating in 0-2000 and 2000-4000 $\mathrm{cm}^{-1}$ ranges. Each spectrograph is equipped with a FFT CCD $1024 \times 58$ pixel array camera operating at $1 \mathrm{kHz}$ at full vertical binning, effectively working as a linear sensor (Entwicklungsbuero Stresing). Both cameras are read simultaneously for each shot, together with a photodiode signal that records the Raman pump pulse energy. This photodiode signal is used for synchronization and parallel detection of the 96 individual FSRS experiments (each obtained with a differently shifted Raman pump wavelength) in 100 ms cycles, where 96 ms is used for recording FSRS and 4 ms for recording transient absorption. This is a compromise between the duration of the experiment and the signal intensity since Raman signals are usually considerably weaker than transient absorption signals, which therefore require shorter acquisition time. The 96 individually shifted Raman signals are recombined into a single spectrum with a highly suppressed baseline and pixelation artifacts by the "watermarking" approach described elsewhere. ${ }^{29}$ Each time-delay point is a result of a 1 minute accumulation time.

For each time delay, a ground- and excited-state Raman, and TA signals are measured. This is achieved by chopping the actinic pump at $500 \mathrm{~Hz}$. To record both ground- and excitedstate Raman signals for each position of the modulator, the phase of the chopper inserted in the actinic beam path is flipped by $180^{\circ}$ at regular intervals. This "phase flip" approach cancels out any artifacts related to irregularities in the Raman pulse modulator shape. ${ }^{29,31}$ Each of the 
two CCD array cameras records a spectral interval approximately $2000 \mathrm{~cm}^{-1}$ wide, covering the 0-2000 $\mathrm{cm}^{-1}$ and $2000-4000 \mathrm{~cm}^{-1}$ ranges, respectively. The signals are numerically stitched together, so the entire $0-4000 \mathrm{~cm}^{-1}$ range is observed simultaneously. Detectors are calibrated by recording FSRS of a 1:1 (v:v) toluene:acetonitrile mixture with accurately known Raman spectrum..$^{32}$

In present experiments, the probe beam was focused to a spot of $\sim 40 \mu \mathrm{m}$ diameter at the sample and overlapped with $\sim 100 \mu \mathrm{m}$ Raman and actinic pump beams. The delay of the actinic pump was scanned from 200 ps before to 6 ns after the arrival of the FSRS probe in 134 logarithmically distributed delay times, providing approximately 8 time points for each doubling of the delay time. Each experiment was repeated several times to verify reproducibility and, for each data point, a median value was selected for analysis. Sample solutions were flowed in a 10x1×1 mm rectangular quartz flow cell (custom-made by Firefly Sci, Inc.). The flow speed was set to ensure a fresh sample spot for each laser shot with a peristaltic pump (mzr-4622-hs-f from HNP Mikrosysteme $\mathrm{GmBH}$ ). Minimal sample damage (below 1\%) was verified by measuring absorption spectra before and after the experiment in a conventional $1 \mathrm{~mm}$ quartz cell (Hellma) in a commercial spectrometer (2800 Shimadzu).

Residual baselines in the data were corrected by fitting $9^{\text {th }}$ order polynomials using the method of least absolute value residuals. In comparison to the least-square fitting, the baseline obtained by this method is less sensitive to sharp changes, for example at bases of narrow peaks. (The least-square procedure by definition fits into the center of the data and thus the baseline does not follow the pedestals of the peaks but goes through their centers. Corrected signals then tend to have a Mexican hat shape. This problem does not occur with least absolute 
residual fitting where polynomial fitting removes the broadband baseline from narrowband peaks at their bases.)

Ground-state FSRS spectra labeled "Exp" and "Exp2" are based on the same raw data but differently analyzed: "Exp" shows data processed by spectral watermarking, ${ }^{29}$ while "Exp 2" spectra were obtained by averaging of shifted signals that were numerically aligned according to their Raman shift. The latter approach produces a spectrum that is very close to the raw single-wavelength FSRS but with an improved fixed-pattern noise as the shifted spectra are recorded at varied positions of the detector. In general, watermarking produces a superior baseline that is, however, prone to specific artifacts when the Raman pulse at $0 \mathrm{~cm}^{-1}$ is scattered within the watermark. Hence, there are only small differences at higher wavenumbers, whereas a notable difference occurs below $400 \mathrm{~cm}^{-1}$. In general, this work shows that measuring very small Raman shifts with FSRS is possible but extra care is required when spectral modulation is applied since peak shapes can change as individual shifted FSRS measurements are in a different state of resonance. ${ }^{33}$ It follows that spectral watermarking will require specific corrections when applied closer to resonance.

\section{Measuring FSRS at low wavenumbers and over broad spectral ranges}

To measure FSRS over a broad wavenumber range, a 2-stage probe preparation was used, whereby the probe is generated from a driving beam whose wavelength is beyond the sensitivity range of the silicon detector. This approach has two key advantages for the FSRS experiment: It allows generating probe pulses that have a flat spectral profile in the 450-1100 $\mathrm{nm}$ interval (or, 350-1100 when $\mathrm{CaF}_{2}$ is used instead of sapphire) and, at the same time, 
exponentially increasing intensity between 1100 and $1200 \mathrm{~nm}$, thus compensating for an exponential loss of the silicon-detector sensitivity in this range. Note that the spectral intensity of a single-filament supercontinuum drops very rapidly upon moving from the generating wavelength and a relatively flat spectral profile is reached only at a substantial distance. Thus, FSRS experiments where the Raman pump and the probe-supercontinuum generating pulses are centered at the same wavelength (often at $800 \mathrm{~nm}$ for Titanium Sapphire lasers) operate in a truncated detection range, as small Raman shifts suffer from an excessive probe intensity, while highly Raman-shifted peaks suffer from a weak probe intensity. Such experiments have narrow effective spectral ranges, with only a few Raman signals in the detection optimum. In contrast, our experimental setting allows recording vibrations in the $40-4000 \mathrm{~cm}^{-1}$ range simultaneously with excellent homogeneous sensitivity. (Performance in the low-end of this range is demonstrated in Figure S9.) This approach is superior to single-stage probe generation either by a single NOPA ${ }^{34}$ or by a single supercontinuum process. ${ }^{35}$ Spectra at low wavenumbers can also be recorded by impulsive stimulated Raman experiments performed in the time domain, ${ }^{36,37}$ however this approach struggles with recording high-energy vibrations since fewcycle pulses as short as $5 \mathrm{fs}$ are required for exciting vibrations at wavenumbers above 2000 $\mathrm{cm}^{-1}$. Moreover, impulsive Raman spectra have to be corrected for the temporal pulse envelope and thus produce patterns that often differ substantially from those recorded by spontaneous Raman scattering. Furthermore, the time-domain approach needs scanning to record spectra and is therefore sensitive to laser instability. In contrast, the FSRS approach used herein allows for simultaneous observation of both low- and high-energy vibrations with a good agreement with spontaneous Raman spectra for each shot. Typically, few thousands shots are 
averaged to achieve a good signal-to-noise ratio, but this process is independent of the shortterm laser instability.

\section{Computational details}

Calculations were performed using Gaussian 16, Revision A.03 $(\mathrm{G} 16)^{38}$ together with the three-parametrized Becke, Lee, Yang, Park (B3LYP) functional. ${ }^{39,40}$ For the Re atom, we used a large basis set $(8 s 7 p 6 d 2 f 1 g) /[6 s 5 p 3 d 2 f 1 g]$ and a standard Stuttgart/Dresden pseudopotential for 60 core electrons. ${ }^{41,42}$ For non-metal atoms we used the $6-31+G(d)$ basis set. ${ }^{43}$ Solvent effects (acetonitrile) were described by the polarizable continuum model (PCM). ${ }^{44}$ The lowest triplet excited state was calculated by the unrestricted Kohn-Sham approach (UKS). Calculations started from a previously optimized structure ${ }^{14}$ that was reoptimized with $\mathrm{G} 16$ and PCM$\mathrm{CH}_{3} \mathrm{CN}$. Triplet-triplet electronic excitations were calculated by time-dependent DFT approach at UKS-optimized geometry.

Anharmonic calculations were based on the second-order vibrational perturbation theory (VPT2) model, ${ }^{11,13,45,46,47}$ which provides an accurate description of anharmonic vibrational energies and wave functions. Fermi and Darling-Dennison resonances were treated by the generalized VPT2 procedure ${ }^{48}$ (GVPT2) on calculated anharmonic potential energy surfaces obtained by the deperturbed VPT2 scheme (DVPT2). Cubic and semidiagonal quartic force constants were computed by numerical differentiation (with displacements of $0.01 \AA$ ) of the analytical Hessian along each active normal coordinate. In the first step, a full dimensionality (FD) calculation included all vibrational modes. Afterwards, large-amplitude motions (LAMs) were identified and their contributions were skipped from GVPT2 calculations. 
Out of the 78 vibrational modes of $\operatorname{ReCl}(\mathrm{CO})_{3}($ bpy $) 53$ and 62 modes were active in calculations of GS and ES spectra, respectively. The VMS-Draw ${ }^{49}$ graphical user interface was used to analyze the outcome of vibrational computations.

\section{- RESULTS}

Time-resolved FSRS of $\operatorname{ReCl}(\mathrm{CO})_{3}$ (bpy) were measured in $\mathrm{CH}_{3} \mathrm{CN}$ and $\mathrm{CD}_{3} \mathrm{CN}$ solutions upon $400 \mathrm{~nm}, 40$ fs excitation into the lowest MLCT absorption band. The $800 \mathrm{~nm}$ Raman pump pulse ( $2 \mathrm{ps}, 16 \mathrm{~cm}^{-1} \mathrm{fwhm}$ ) is out-of-resonance for the ground state whose lowest allowed electronic absorption band occurs at $371 \mathrm{~nm} \cdot{ }^{28,50}$ On the other hand, the Raman pump falls into the weak/broad absorption of the lowest ${ }^{3} \mathrm{MLCT}$ excited state that originates from $\pi \pi^{*}$ transitions localized at the bpy ${ }^{--}$ligand (Figure S1). ${ }^{51,52}$ The broad-band white-light continuum (Raman probe) was generated using pulses at a wavelength $(1400 \mathrm{~nm})$ longer than that of the Raman pump in order to achieve a relatively smooth/flat profile in the $800-1200 \mathrm{~nm}$ interval where the Raman signals occur, thus enabling to measure spectra at small Raman shifts values, from ca. $40 \mathrm{~cm}^{-1}$. Additionally, we used watermarking, ${ }^{29}$ whereby multiple experiments with slightly shifted Raman wavelengths are performed in parallel and recombined into a single Raman spectrum with a greatly improved baseline and decreased fixed-pattern noise. These two technical innovations allowed us to obtain good-quality spectra over a very broad spectral range.

Ground-and excited-state Raman spectra and their assignment 
Ground-state FSRS of $\operatorname{ReCl}(\mathrm{CO})_{3}($ bpy $)$ spectra are shown in Figures 1 and S2, together with those calculated using harmonic and anharmonic approximations. The peak wavenumbers are summarized in Table 1 and selected vibrational modes are visualized in Chart S1. Anharmonically calculated wavenumbers and the overall spectral pattern match well the experimental spectrum, except for the $v(C O)$ vibrations whose wavenumbers were calculated accurately (as compared with IR values ${ }^{14}$ ) but the theoretical Raman intensities are much higher than the weak signals apparent in $\mathrm{CH}_{3} \mathrm{CN}$ (Figure S2). A strong band belonging to bpy-ring $\mathrm{CC}$ and $\mathrm{CN}$ stretching vibrations occur at $1600-1605 \mathrm{~cm}^{-1}$ whereas the predominantly inter-ring $v(C C)$ band is observed at $1490-1493 \mathrm{~cm}^{-1}$. Inter-ring stretching contributes to several other modes as well, especially to the intense feature at 1314-1319 $\mathrm{cm}^{-1}$. Re-CO stretching vibrations are observed at $\sim 479$ and $500-507 \mathrm{~cm}^{-1}$, usually coupled with ReCO deformations. The Re-Cl stretch makes the principal contribution to the $239-243 \mathrm{~cm}^{-1}$ feature, while also contributing to the modes at 256-265 and $115 \mathrm{~cm}^{-1}$, where it is usually coupled with deformations of the Re(bpy) moiety. Few bands deviate from the anharmonically calculated spectrum. Namely, the calculation overestimates vibrational wavenumbers in the $1550-1650 \mathrm{~cm}^{-1}$ range. The feature observed at $1568\left(\mathrm{CH}_{3} \mathrm{CN}\right)$ and $1557 \mathrm{~cm}^{-1}\left(\mathrm{CD}_{3} \mathrm{CN}\right)$ was thus tentatively attributed to the $v(\mathrm{CN}$, CC) mode 64 calculated at $1600 \mathrm{~cm}^{-1}$, with a possible contribution from a $52+20$ combination band calculated at $1581 \mathrm{~cm}^{-1}$. The strong band at $1600-1605 \mathrm{~cm}^{-1}$ most likely encompasses $v(C N, C C)$ modes 66 and 67 calculated at 1622 and $1633 \mathrm{~cm}^{-1}$, respectively. Features at 1368 (possibly solvent) and $915 \mathrm{~cm}^{-1}$ also do not match any calculated strong Raman band and their assignment (Table 1) remains tentative. 

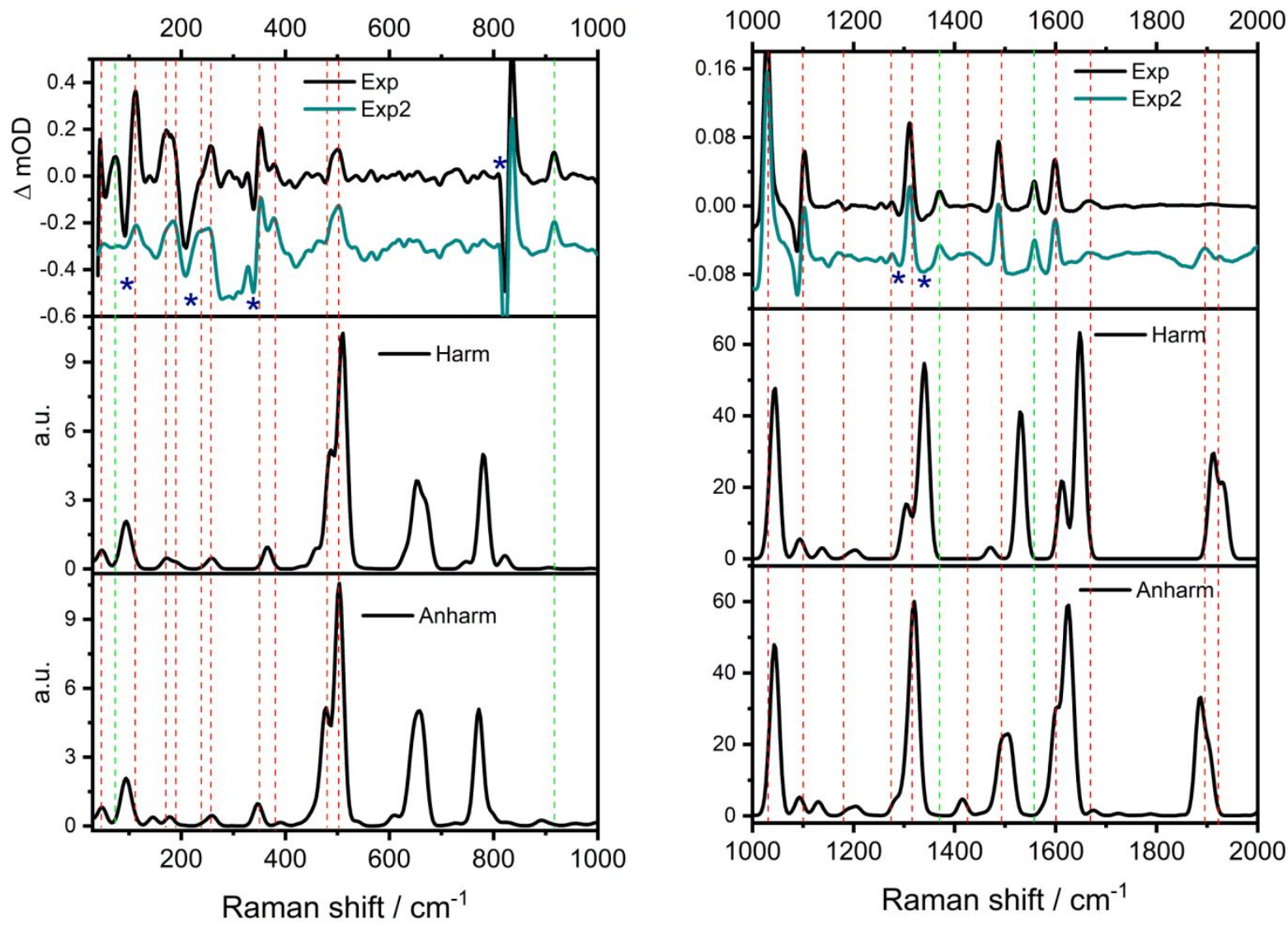

Figure 1. Ground-state FSRS of $\operatorname{ReCl}(\mathrm{CO})_{3}(\mathrm{bpy})$ in $\mathrm{CD}_{3} \mathrm{CN}$ (top), together with harmonically (middle) and anharmonically (bottom) calculated Raman spectra. Exp and Exp2 spectra in the top panel originated from the same raw data that were analyzed using "watermarking" and averaging of shifted signals, respectively. (See the Experimental section.) Red vertical lines connect experimental and corresponding anharmonically (bottom) calculated Raman features. Green vertical lines show experimental Raman bands without obvious calculated counterparts. * denotes residual solvent features and background artifacts. a.u. = arbitrary units. No significant spectral features were observed between 2000 and $4000 \mathrm{~cm}^{-1}$. Spectra measured in $\mathrm{CH}_{3} \mathrm{CN}$ are shown in Figure $\mathrm{S} 2$. 
Table 1. Experimentala and calculated Raman spectra of ground-state $\operatorname{ReCl}(\mathrm{CO})_{3}(\mathrm{bpy})$.

\begin{tabular}{|c|c|c|c|c|c|}
\hline$\#^{\mathrm{b}}$ & Principal vibrations ${ }^{c}$ & Experimental & Harmonic & Anharmonic & $\begin{array}{l}\text { Relative } \\
\text { int. }^{c}\end{array}$ \\
\hline 70 & $v(\mathrm{CO})$ & 2021 & 2054 & 2024 & 20.5 \\
\hline 69 & $v(\mathrm{CO})_{\text {asym }, \mathrm{eq}}$ & 1916 & 1932 & 1904 & 33 \\
\hline \multirow[t]{2}{*}{68} & $v(\mathrm{CO})_{\mathrm{ax}}+v(\mathrm{CO})_{\mathrm{sym}, \mathrm{eq}}$ & 1894 & 1911 & 1884 & 59.6 \\
\hline & $58+17$ & 1666 & - & 1675 & 3.2 \\
\hline 67 & $v(\mathrm{CN}, \mathrm{CC})$ & \multirow{2}{*}{$1605(1600)$} & 1655 & 1633 & 40.8 \\
\hline 66 & $v(\mathrm{CC})_{\text {ring }}$ & & 1647 & $1622^{*}$ & 78.2 \\
\hline \multirow[t]{2}{*}{64} & $v(\mathrm{CN}, \mathrm{CC})$ & \multirow{2}{*}{$1568(1557)$} & 1612 & $1600 *$ & 55.9 \\
\hline & $52+20$ & & - & 1581 & 4.4 \\
\hline \multirow[t]{3}{*}{63} & $v(\mathrm{CC}$ inter-ring, $\mathrm{CC})+\delta(\mathrm{CH})$ & \multirow{2}{*}{$1493(1490)$} & 1531 & $1510^{*}$ & 39.7 \\
\hline & $58+12$ & & - & 1493 & 34.4 \\
\hline & $40+28$ & $(1425)$ & - & 1426 & 0.8 \\
\hline 60 & $v(\mathrm{CN}, \mathrm{CC}, \mathrm{CC}$-inter-ring) & $1410 ?$ & 1471 & $1415^{*}$ & 8.4 \\
\hline 59 & $v(\mathrm{CC})+\delta(\mathrm{bpy}, \mathrm{CH})$ & $(1368)$ & 1351 & 1351 & 1.2 \\
\hline 58 & $v(\mathrm{CC}$ inter-ring, $\mathrm{CN})+\delta(\mathrm{CH})$ & $1319(1314)$ & 1340 & 1319* & 100 \\
\hline 55 & $v(\mathrm{CN}), \delta(\mathrm{CH})$ & $(1275)$ & 1299 & 1283 & 8.6 \\
\hline 53 & $\delta(\mathrm{CH})$ & $(\sim 1181) ?$ & 1191 & 1188 & 3.4 \\
\hline 52 & $\delta(\mathrm{CH})$ & - & 1152 & 1135 & 1.2 \\
\hline 49 & $v(\mathrm{CC}), \delta(\mathrm{CH})$ & $(1100)$ & 1093 & 1093* & 10.5 \\
\hline 47 & $\delta(\text { bpy })_{\text {sym }}$-breath $+\delta$ Rebpy & \multirow{2}{*}{$1033(1030)$} & 1044 & $1044^{*}$ & 91.9 \\
\hline \multirow[t]{2}{*}{46} & $\delta(\text { bpy })_{\text {antisym }}$-breath $+\delta$ Rebpy & & 1034 & $1034^{*}$ & 12.4 \\
\hline & $28+21$ & (970) & - & 975 & 0.002 \\
\hline \multirow[t]{2}{*}{41} & $\delta(\mathrm{CH})_{\text {sym, out-plane }}$ & \multirow{3}{*}{$(915)$} & 909 & 909 & 0.1 \\
\hline & 20 overtone & & - & 893 & 0.3 \\
\hline 40 & $\delta(\mathrm{CH})_{\text {antisym, out-plane }}$ & & 901 & 886 & 0.2 \\
\hline 38 & $\delta(\text { bpy })_{\text {sym }}$-breath & $767 ?$ & 781 & 771 & 10.2 \\
\hline 35 & $\delta(\mathrm{CH})_{\text {sym }}+v(\mathrm{CC}$ inter-ring $)$ & - & 745 & 727 & 0.2 \\
\hline 32 & $v(\operatorname{ReN}), \delta(C C)$ & - & 652 & 649 & 6.3 \\
\hline 30 & $\delta(\operatorname{Re}-\mathrm{C}-\mathrm{O})$ & - & 632 & 607 & 0.8 \\
\hline 28 & $\delta(\mathrm{CC}, \mathrm{CH})_{\text {antisym, out-plane }}$ & - & 563 & 537 & 0.2 \\
\hline 25 & $\begin{array}{c}v(\operatorname{Re}-\mathrm{CO})_{\mathrm{ax}} \\
\delta(\operatorname{Re}-\mathrm{C}-\mathrm{O})_{\mathrm{eq}}\end{array}$ & $507(500)$ & 510 & $504 *$ & 20.5 \\
\hline \multirow[t]{2}{*}{23} & $\begin{array}{l}v(\operatorname{Re}-\mathrm{CO})_{\mathrm{eq}} \\
\delta(\operatorname{Re}-\mathrm{C}-\mathrm{O})_{\mathrm{ax}}\end{array}$ & $(479)$ & 486 & $478 *$ & 5.9 \\
\hline & - & 432 & - & - & \\
\hline 21 & $\delta(C C)+\delta($ Rebpy) & - & 460 & 456 & 1.4 \\
\hline 20 & $\begin{array}{c}\delta(\mathrm{CC}, \mathrm{CH})_{\text {antisym, out-plane }} \\
\delta(\mathrm{O}-\mathrm{C}-\mathrm{Re})\end{array}$ & - & 456 & 442 & 0.4 \\
\hline 18 & $\delta(\mathrm{CC}, \mathrm{CH})_{\text {sym }, \text { out-plane }}$ & $(380)$ & 430 & 390 & 0.3 \\
\hline \multirow[t]{2}{*}{17} & $\delta(\text { bpy })_{\text {out-plane }}$ & $(352)$ & 365 & $347^{*}$ & 1.9 \\
\hline & - & $311(307)$ & - & - & \\
\hline
\end{tabular}




\begin{tabular}{|c|c|c|c|c|c|}
\hline & - & (290) & - & - & \\
\hline 16 & $\delta(\text { bpy })_{\text {out-plane }}+v(\operatorname{ReCl})$ & \multirow{2}{*}{$265(256)$} & 261 & $261 *$ & 0.4 \\
\hline 15 & $\delta(\text { bpy })_{\text {out-plane }}+v(\operatorname{ReCl})$ & & 259 & $259 *$ & 0.5 \\
\hline 14 & $v(\operatorname{ReCl})+\delta(\operatorname{Rebpy})$ & $243(239)$ & 248 & $244^{*}$ & 0.3 \\
\hline 12 & $\delta(\text { bpy })_{\text {sym, out-plane }}+\delta($ Rebpy $)$ & $\begin{array}{c}(189) \\
177(170)\end{array}$ & 190 & $178^{*}$ & 0.8 \\
\hline 10 & $\delta(\text { bpy })_{\text {antisym, out-plane }}+\delta(\operatorname{ReCl})$ & \multirow{2}{*}{$(115)$} & 107 & 107 & 0.6 \\
\hline 9 & $\delta(\operatorname{ReCl})+\delta($ bpy $)+\delta(\operatorname{ReCO})$ & & 100 & 100 & 0.5 \\
\hline 8 & $\delta($ bpy $)+\delta(\mathrm{CO})$ & \multirow{3}{*}{-} & 95 & 95 & 1.1 \\
\hline 7 & $\delta(\mathrm{CO})+\delta(\operatorname{ReCl})$ & & 94 & 94 & 1.4 \\
\hline 6 & $\delta(\operatorname{ReCO})+\delta(\mathrm{CReCl})+\delta(\mathrm{bpy})$ & & 92 & 92 & 1 \\
\hline 2 & $\delta($ bpy $)+\delta(\operatorname{ReCO})+\delta(\operatorname{ReCl})$ & (45) ? & 48 & 48 & 1.7 \\
\hline
\end{tabular}

a Data from $\mathrm{CH}_{3} \mathrm{CN}$ or $\left(\mathrm{CD}_{3} \mathrm{CN}\right)$ solutions. No significant spectral features were observed between 2000 and $4000 \mathrm{~cm}^{-1}$. ? after an experimental wavenumber indicates a weak or uncertain feature. ${ }^{b}$ Normal mode number in the order of increasing frequency. ${ }^{c}$ Based on anharmonic calculation. Deformations of the Rebpy moiety ( $\delta$ (Rebpy)) involve ReN stretches. * Vibration shown in Chart S1.

Excited-state FSRS measured at 60 ps when the ${ }^{3}$ MLCT state is thermalized ${ }^{25,26,53,54}$ is compared with theoretical spectra in Figures 2, S3. Anharmonic vibrational analysis of the UKSDFT optimized lowest ${ }^{3}$ MLCT excited state identified excited-state Raman features and characterized the corresponding vibrations (Table 2, Chart S2). A good match between calculated and experimental frequencies was obtained while the intensity patterns are not directly comparable since experimental intensities are partly affected by resonance with $\pi \pi^{*}\left(\mathrm{bpy}^{\bullet-}\right)$ transitions (Figure S1). Thus, the most intense calculated Raman band due to the totally symmetric in-phase $v(\mathrm{CO})$ vibration is not observed in the experimental spectrum whereas bpy - - vibrations and some of the low-frequency modes give rise to well-developed signals. Calculations also provided the Duschinsky matrix (Figures 3, S4) that correlates groundand excited-state vibrations. The matrix shows considerable remixing among $\mathrm{CC}$ and $\mathrm{CN}$ stretching and $\mathrm{CH}$ bending modes of the bpy ligand (55-67) on going to the excited state. For 
example, the excited-state mode 67 contains $22 \%$ and $65 \%$ contributions of ground-state $v(C C$, $\mathrm{CN}$ ) modes 65 and 67, respectively. The predominantly inter-ring CC stretch ground-state mode 58 at $1314-1319 \mathrm{~cm}^{-1}$ contributes to excited-state vibrations $57\left(26 \%\right.$, at $\left.\sim 1278 \mathrm{~cm}^{-1}\right)$ and 59 $\left(61 \%\right.$, at $\left.1370 \mathrm{~cm}^{-1}\right)$ and to a host of higher-lying modes. Remixing also occurs between $\delta($ bpy $) / \delta(\mathrm{CH}) / \delta$ (Rebpy) modes $40-53$, deformation and Re-CO stretching vibrations $20-30$, the group of related $v(\operatorname{ReCl}) / \delta($ Rebpy) vibrations $14-16$, as well as among low-frequency modes $1-$ 10.

Excited-state FSRS shows strong $v(\mathrm{CC}, \mathrm{CN})$ and $v$ (CC-ring, inter-ring) features at $\sim 1550$ and $\sim 1500 \mathrm{~cm}^{-1}$, respectively. The inter-ring CC stretch contributes to vibrations $64,63,60$, and 59 that occur in the range $1370-1500 \mathrm{~cm}^{-1}$. However, the only modes well visible in the spectrum are $64\left(1502 \mathrm{~cm}^{-1}\right)$ and $60\left(\sim 1420 \mathrm{~cm}^{-1}\right)$. The band due to the principal $v(\mathrm{CC}$ interring) mode $59\left(1370 \mathrm{~cm}^{-1}\right)$ is barely apparent, in contrast to the corresponding strong GS feature 58 at $1314-1319 \mathrm{~cm}^{-1}$. On the other hand, the excited-state spectrum shows bands at $\sim 1174(\delta(\mathrm{CH})), 1217(\delta(\mathrm{CH}))$, and $\sim 1278(\mathrm{v}(\mathrm{CC}, \mathrm{CN})) \mathrm{cm}^{-1}$ that do not have strong counterparts in the ground-state spectrum, whereas the strongest ground-state $\delta$ (bpy-breathing)/ $\delta$ Rebpy feature at $1033 \mathrm{~cm}^{-1}$ shifts to $\sim 1008 \mathrm{~cm}^{-1}$ and decreases in intensity. The low-frequency region exhibits features due to deformation vibrations of the bpy ${ }^{\bullet-}$ ligand and the Re $\mathrm{R}^{\prime \prime}\left(\mathrm{bpy}^{\bullet-}\right)$ chelate ring $\left(522-525,632, \sim 661,710 \mathrm{~cm}^{-1}\right)$, an Re-CO stretch at 375, 402-409, 436-443 $\mathrm{cm}^{-1}$, and ReCO deformations $\left(436-443, \sim 471,539-593 \mathrm{~cm}^{-1}\right)$. The principal mode involving the Re-Cl stretch was observed at $266-277 \mathrm{~cm}^{-1} . v(\mathrm{ReCl})$ also contributes to the features at $245-253$ and $\sim 200$ $\mathrm{cm}^{-1}$, coupled with out-of-plane bpy ${ }^{\bullet-}$ and $\operatorname{Re}^{\prime \prime}\left(\mathrm{bpy}^{\bullet-}\right)$ deformations. 

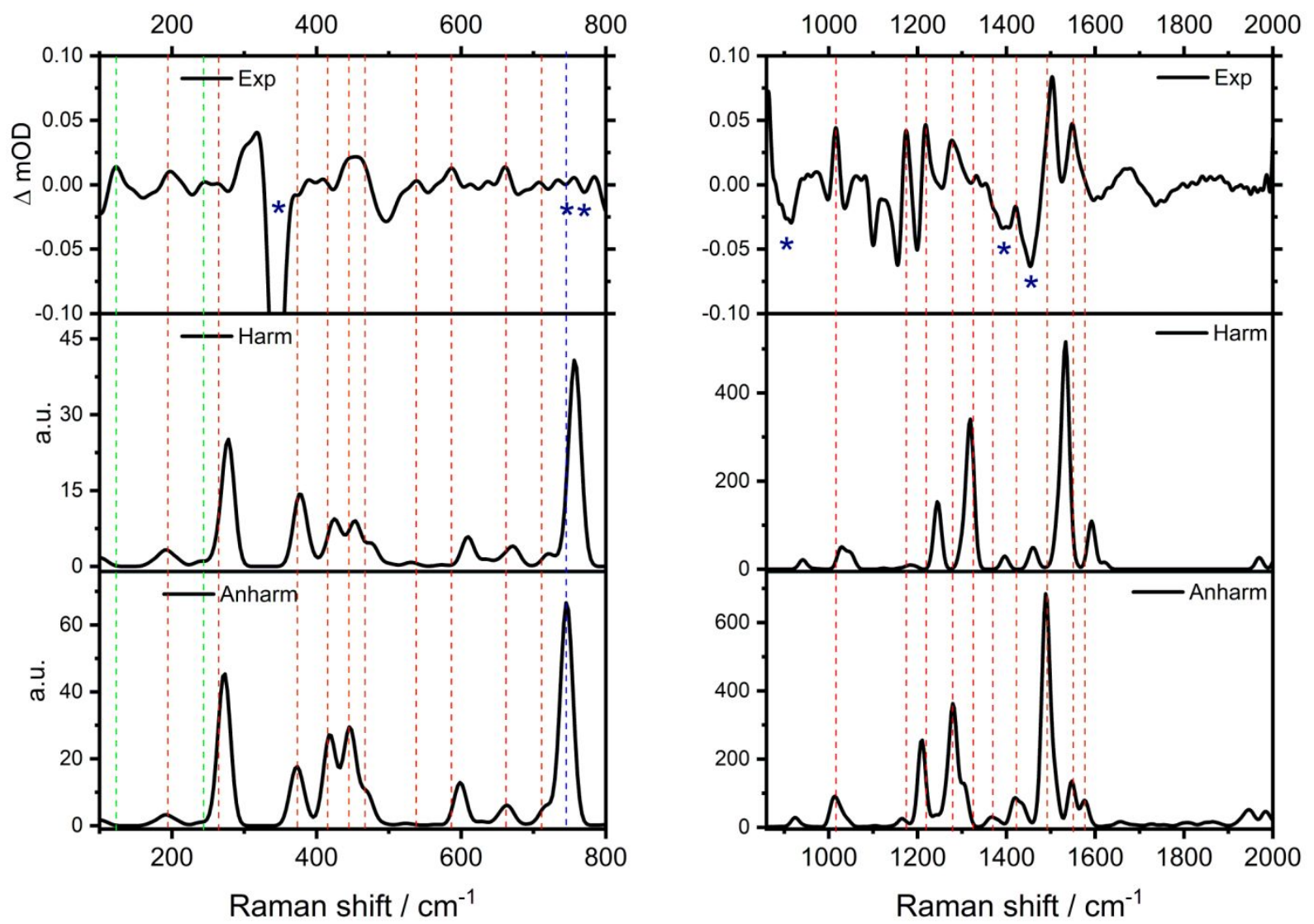

Figure 2. FSRS of the lowest electronic excited state of $\operatorname{ReCl}(\mathrm{CO})_{3}(\mathrm{bpy})$ in $\mathrm{CD}_{3} \mathrm{CN}$ measured $60 \mathrm{ps}$ after $400 \mathrm{~nm}$ excitation (top), together with harmonically (middle) and anharmonically (bottom) calculated Raman spectra. Red lines connect experimental and corresponding anharmonically calculated Raman features. Green lines show experimental Raman bands without obvious calculated counterparts. Blue line: Calculated band without an experimental counterpart presumably due to overlapping solvent features. ${ }^{*}$ denotes residual solvent features and background artifacts. No experimental features detected between 2000 and $4000 \mathrm{~cm}^{-1}$. Spectra measured in $\mathrm{CH}_{3} \mathrm{CN}$ are shown in Figure S3. (a.u. = arbitrary units)

Table 2. Experimental ${ }^{a}$ and calculated Raman spectra of the lowest electronic excited state $\operatorname{ReCl}(\mathrm{CO})_{3}(\mathrm{bpy})$.

\begin{tabular}{|c|c|c|c|c|c|}
\hline$\#^{\mathrm{b}}$ & Principal vibrations ${ }^{\mathrm{c}}$ & Experimental & Harmonic & Anharmonic & $\begin{array}{c}\text { Relative } \\
\text { int. }{ }^{c}\end{array}$ \\
\hline 70 & $v(\mathrm{CO})_{\text {sym }}$ & 2053 & 2086 & 2052 & 100 \\
\hline 69 & $v(\mathrm{CO})_{\mathrm{ax}}+v(\mathrm{CO})_{\mathrm{sym}, \mathrm{eq}}$ & 1985 & 2012 & 1981 & 4.7 \\
\hline \multirow[t]{2}{*}{68} & $v(\mathrm{CO})_{\text {asym }, \mathrm{eq}}$ & 1940 & 1969 & 1945 & 4.3 \\
\hline & $63+18$ & $1868(1884)$ & - & 1865 & 0.8 \\
\hline 67 & $v(\mathrm{CC}, \mathrm{CN})$ & $1579(1577)^{d}$ & 1621 & $1576^{*}$ & 3.6 \\
\hline
\end{tabular}




\begin{tabular}{|c|c|c|c|c|c|}
\hline 66 & $v(\mathrm{CC}, \mathrm{CN})$ & $1548(1550)$ & 1592 & $1546^{*}$ & 18.3 \\
\hline 64 & $v(C C$ inter-ring $)+v(C C)$ & $1500(1502)$ & 1534 & $1490 *$ & 72.4 \\
\hline 63 & $v(\mathrm{CC}, \mathrm{CN}, \mathrm{CC}$ inter-ring $)$ & $\begin{array}{c}1477(1482) \\
\text { shoulder }\end{array}$ & 1516 & $1484^{*}$ & 2.1 \\
\hline 60 & $\delta(\mathrm{CH})+v(\mathrm{CN}, \mathrm{CC}$ inter-ring $)$ & $1422(1421)$ & 1456 & 1417 & 11.9 \\
\hline 59 & $v(\mathrm{CC}$ inter-ring $)+\delta(\mathrm{CH})$ & $(1370)$ & 1396 & 1363 & 3.3 \\
\hline 57 & $v(\mathrm{CN}, \mathrm{CC})$ & $1279(1277)$ & 1318 & $1280 *$ & 52 \\
\hline 55 & $\delta(\mathrm{CH})$ & $1217(1218)$ & 1245 & 1209* & 39 \\
\hline 53 & $\delta(\mathrm{CH})$ & $1175(1173)$ & 1179 & 1164 & 3.3 \\
\hline & 27 overtone & 1057 & - & 1042 & 1.9 \\
\hline 48 & $v(\mathrm{CC})+v(\mathrm{CN})$ & \multirow{2}{*}{$1008(1016)$} & 1038 & $1021^{*}$ & 3.6 \\
\hline 47 & $\delta$ (bpy-breath) $+\delta$ (Rebpy) & & 1027 & $1010^{*}$ & 9.1 \\
\hline & $31+18$ & $980(972)$ & - & 977 & 0.1 \\
\hline & 25 overtone & \multirow[t]{2}{*}{ 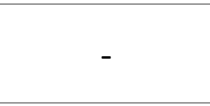 } & - & 940 & 0.3 \\
\hline 42 & $\delta(\text { bpy-breath })_{\text {antisym }}+\delta($ Rebpy $)$ & & & 923 & 4 \\
\hline \multirow{2}{*}{40} & \multirow{2}{*}{$\delta(\mathrm{CH})_{\text {antisym, out-plane }}$} & 843 & \multirow{2}{*}{836} & \multirow{2}{*}{824} & 0.3 \\
\hline & & 815 & & & 0.3 \\
\hline 38 & $\delta(\text { bpy-breath })_{\text {sym }}$ & 767 & 757 & 746 & 9.3 \\
\hline 36 & $\delta(\text { bpy) })_{\text {out-plane }}$ & $711(708)$ & 720 & 716 & 0.6 \\
\hline 35 & $\delta(\text { bpy })_{\text {out-plane }}$ & \multirow{3}{*}{$\begin{array}{c}\sim 650,684 \\
(661)\end{array}$} & 681 & 671 & 0.1 \\
\hline 34 & $\delta($ bpy $)+\delta$ (Rebpy) & & 672 & 665 & 0.7 \\
\hline 33 & $\delta($ bpy $)+\delta$ (Rebpy) & & 657 & 654 & 0.6 \\
\hline 32 & $\delta($ bpy $)+\delta($ Rebpy) & 632 & 635 & 628 & 0.2 \\
\hline 31 & $\delta(\operatorname{Re}-\mathrm{C}-\mathrm{O})$ & $597(587)$ & 609 & 599* & 2 \\
\hline $30^{\mathrm{e}}$ & $\delta(\operatorname{Re}-\mathrm{C}-\mathrm{O})$ & $559(539)$ & $573 ?$ & $564 ?$ & 0.1 \\
\hline 28 & $\delta(\text { bpy })_{\text {out-plane }}$ & $525(522)$ & 529 & 520 & 0.1 \\
\hline 27 & $\delta($ Re-C-O $)+\delta(\text { bpy })_{\text {out-plane }}$ & - & 500 & 492 & 0.1 \\
\hline 26 & $\delta($ Re-C-O $)+\delta(\text { bpy })_{\text {out-plane }}$ & $470(\sim 472)$ & 477 & $471^{*}$ & 1.2 \\
\hline 25 & $\delta(\operatorname{Re}-\mathrm{C}-\mathrm{O})+\delta(\mathrm{bpy})$ & - & 466 & 463 & 0.4 \\
\hline 24 & $\begin{array}{c}v(\operatorname{Re}-\mathrm{CO})_{\mathrm{eq}}+\delta(\operatorname{Re}-\mathrm{C}-\mathrm{O})_{\mathrm{ax}}+ \\
\delta(\operatorname{Rebpy})\end{array}$ & \multirow[t]{2}{*}{$436(443)$} & 453 & $447^{*}$ & 4.1 \\
\hline 23 & $\delta(\text { bpy })_{\text {out-plane }}+\delta(\operatorname{Re}-\mathrm{C}-\mathrm{O})$ & & 437 & $436^{*}$ & 0.7 \\
\hline 21 & $v(\text { Re-CO })_{\mathrm{ax}}+\delta(\mathrm{bpy})_{\text {out-plane }}$ & 402 (409) & 423 & 418 & 3.5 \\
\hline 18 & $v(\operatorname{Re}-\mathrm{CO})_{\text {eq,antisym }}+\delta(\operatorname{Rebpy})$ & \multirow{2}{*}{$(375)$} & 384 & 379 & 1 \\
\hline 17 & $\delta(\text { bpy })_{\text {out-plane }}$ & & 375 & $370 *$ & 2.1 \\
\hline 16 & $v(\operatorname{ReCl})+\delta(\operatorname{Rebpy})$ & $277(266)$ & 278 & $273^{*}$ & 6.9 \\
\hline 15 & $\delta($ Rebpy $)+v(\operatorname{ReCl})$ & $253(245)$ & 263 & $263^{*}$ & 0.4 \\
\hline 14 & $\delta(\text { bpy })_{\text {out-plane }}$ & 236 & 239 & 239 & 0.2 \\
\hline 13 & $\delta(\text { bpy })_{\text {out-plane }}$ & 213 & 206 & 206 & 0.2 \\
\hline 12 & $\delta(\text { bpy })_{\text {out-plane }}+\delta(\operatorname{Re}-\mathrm{Cl})$ & \multirow{2}{*}{$200(198)$} & 191 & $191 *$ & 0.4 \\
\hline 11 & $\delta(\text { bpy })_{\text {out-plane }}+\delta$ (Rebpy) & & 175 & 175 & 0.1 \\
\hline 10 & Deformation & $128(122)$ & 106 & 106 & 0.1 \\
\hline
\end{tabular}

a Data from $\mathrm{CH}_{3} \mathrm{CN}$ or $\left(\mathrm{CD}_{3} \mathrm{CN}\right)$ solutions. No features detected between 2000 and $4000 \mathrm{~cm}^{-1}$. b Normal mode number in the order of increasing frequency. ${ }^{\mathrm{c}}$ Based on anharmonic calculation. 
Deformations of the Rebpy moiety ( $\delta$ (Rebpy)) involve ReN stretches. ${ }^{d}$ Determined by Gaussian decomposition, see the text. e Tentative assignment (calculated with a very small intensity). ${ }^{*}$ Vibration shown in Chart S2.

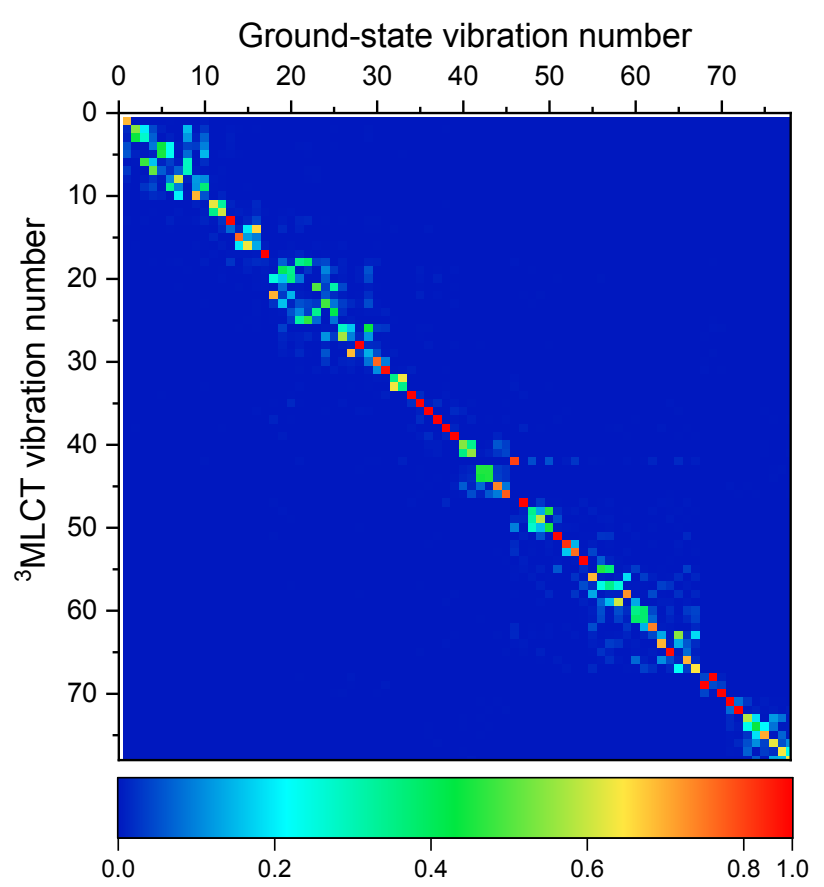

Figure 3. Duschinsky matrix of anharmonically calculated vibrations of $\operatorname{ReCl}(\mathrm{CO})_{3}(\mathrm{bpy})$ in the ground- and lowest ${ }^{3} \mathrm{MLCT}$ states. The matrix shows excited-state vibrations as a linear combination of ground-state vibrations (horizontally) and vice-versa (vertically). The corresponding shift-vector diagram is shown in Figure S5.

Time-resolved excited-state Raman spectra (Figures 4, S6) show dramatic changes in the 1450-1600 $\mathrm{cm}^{-1}$ region where a group of features due to high-frequency bpy ${ }^{\bullet-} \mathrm{CC}$ and $\mathrm{CN}$ stretching vibrations 63-67 emerges between 150 and $200 \mathrm{fs}$ and then grows over the next few tens of picoseconds (Figures 5A, B). The integrated area of the corresponding bands grows with a biexponential kinetics (380 fs, 65\%; 21 ps, 35\%; Figures 5C and S7). Bandwidths show a small initial rise followed by narrowing with a maximum at $\sim 3 \mathrm{ps}$ (for the $1551 \mathrm{~cm}^{-1}$ band, Figure $5 \mathrm{D}$ ). The peak maximum of the strongest band shifts from $1496 \mathrm{~cm}^{-1}$ at $200 \mathrm{fs}$ to $1502 \mathrm{~cm}^{-1}$ at $30 \mathrm{ps}$ and later. The $\sim 1546 \mathrm{~cm}^{-1}$ feature undergoes a small upshift and band-shape changes. More 
pronounced restructuring of the $1450-1600 \mathrm{~cm}^{-1}$ spectral pattern takes place at the earliest investigated times, from 40 to $200 \mathrm{fs}$ (Figure 5B). The initial spectrum recorded at $40 \mathrm{fs}$ shows spectral features at ca. 1486, 1514, 1532, and $1552 \mathrm{~cm}^{-1}$ that all gradually shift to higher wavenumbers. The $1514 \mathrm{~cm}^{-1}$ band concomitantly decreases in intensity and eventually (200$300 \mathrm{fs}$ ) disappears, whereas the latter two merge into the $1546 \mathrm{~cm}^{-1}$ feature showing a 1573 $\mathrm{cm}^{-1}$ shoulder. Mid-range spectral features are largely developed already at $150 \mathrm{fs}$ and show only limited dynamics, usually small picosecond upshifts and growth, commensurate with the $\sim 21$ ps growth component identified in the $1450-1600 \mathrm{~cm}^{-1}$ range. This is the case, for example, of the bands at 1212 and $1273 \mathrm{~cm}^{-1}$ that shift to $\sim 1217$ and $\sim 1278 \mathrm{~cm}^{-1}$, respectively, while that at $1171 \mathrm{~cm}^{-1}$ moves less, to $1174 \mathrm{~cm}^{-1}$. More interesting dynamics occurs in the lowfrequency range (Figure 6), where the features at 583 and $665 \mathrm{~cm}^{-1}$ (in $\mathrm{CD}_{3} \mathrm{CN}$ ) and 560-585 $\mathrm{cm}^{-1}\left(\mathrm{CH}_{3} \mathrm{CN}\right)$ decrease in intensity during the first $300 \mathrm{fs}$ whereas the lowest band increases and shifts from $\sim 112$ (at $150 \mathrm{fs}$ ) to $124 \mathrm{~cm}^{-1}$ during the first 2 ps. Early band restructuring around 200 and $\sim 580 \mathrm{~cm}^{-1}$ will be discussed below, in the context of intersystem crossing.
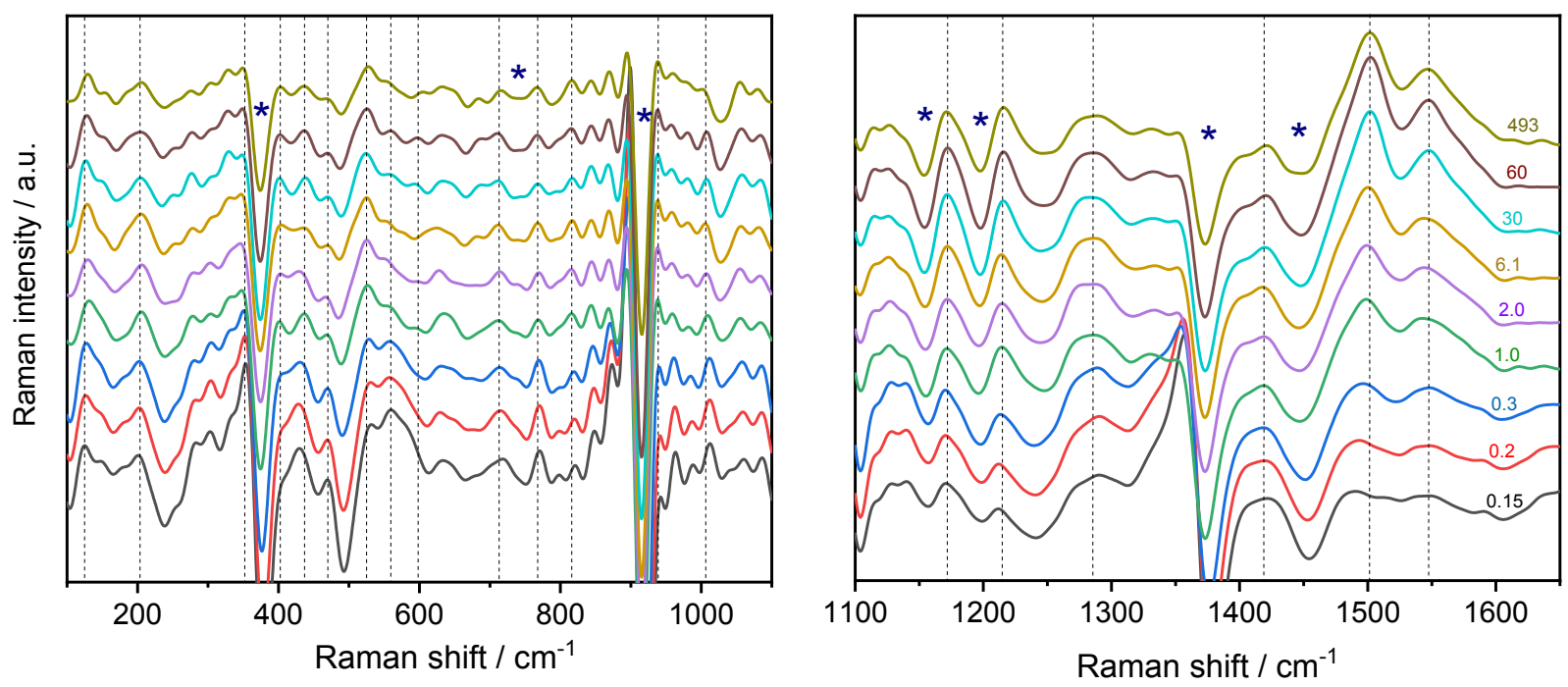
Figure 4. Time evolution of $\mathrm{FSRS}$ of $\mathrm{ReCl}(\mathrm{CO})_{3}(\mathrm{bpy})$ in $\mathrm{CH}_{3} \mathrm{CN}$ measured (from bottom to the top) at $0.15,0.2,0.3,1.0,2.0,6.1,30,60$, and 493 ps. The spectra are offset by a constant amount for better visibility. The dotted lines show band positions in the 60 ps spectrum. * Solvent or background features. Spectra in $\mathrm{CD}_{3} \mathrm{CN}$ are shown in Figure $\mathrm{S6}$.
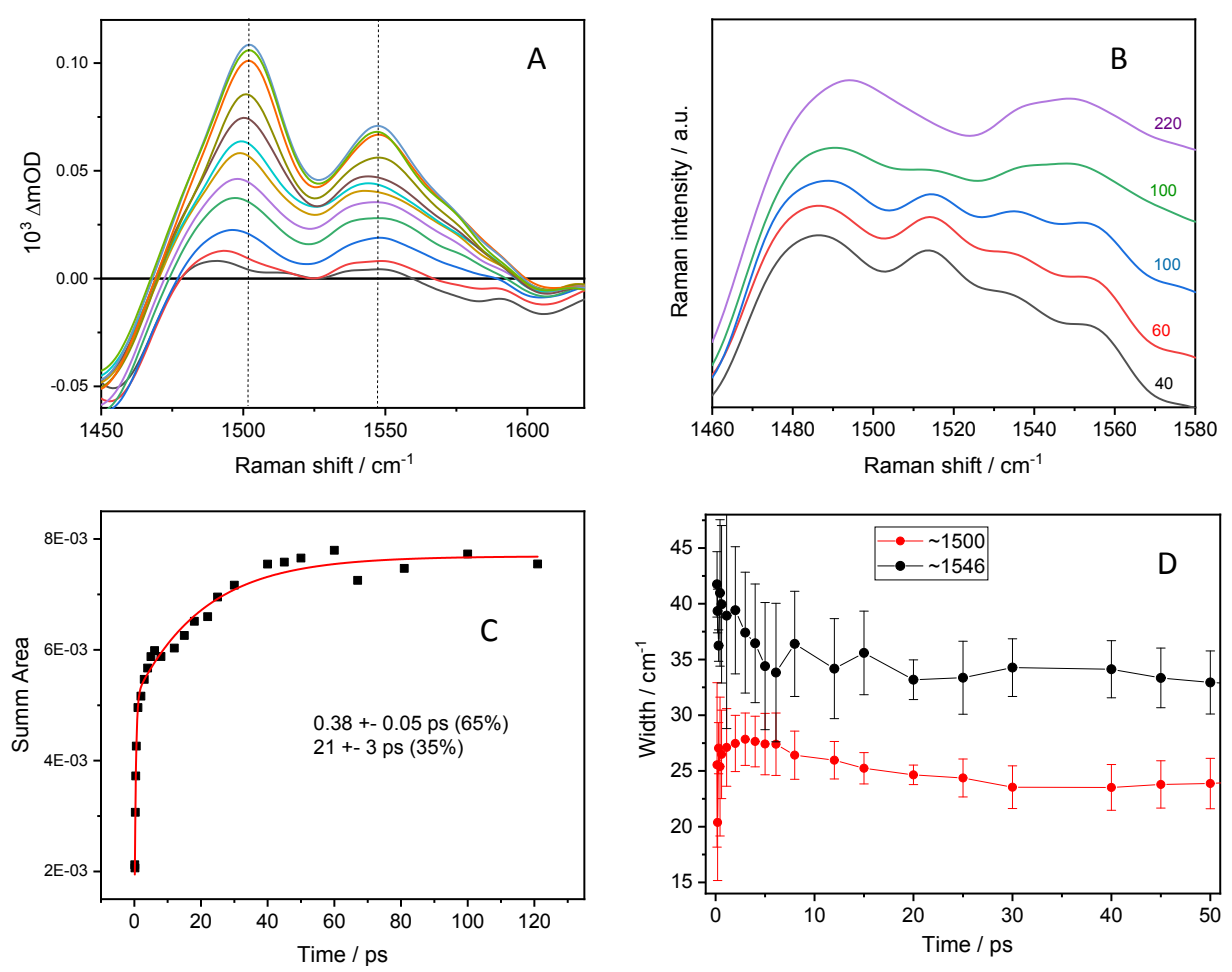

Figure 5. Dynamics of Raman bands in the $1450-1600 \mathrm{~cm}^{-1}$ range measured in $\mathrm{CH}_{3} \mathrm{CN}$. A: Timeresolved spectra adjusted to a common zero-signal level. Time delays from bottom up: 0.15 , $0.20,0.30,0.45,0.61,1.1,2.0,6.1,14.9,30,60,122 \mathrm{ps}$. The dotted lines show band positions in the 60 ps spectrum. B: Detail of the spectral evolution from 40 to $220 \mathrm{fs}$; spectra are offset by a constant amount. C: Time-dependence of the sum of band areas in the $1450-1600 \mathrm{~cm}^{-1}$ range. (Time-dependence of the $\sim 1500 \mathrm{~cm}^{-1}$ band area alone is shown in Figure S7.) D: Timedependence of the widths (fwhm) of $\sim 1500$ and $1546 \mathrm{~cm}^{-1}$ Raman features. (Band areas and widths were obtained by Gaussian decomposition.) 

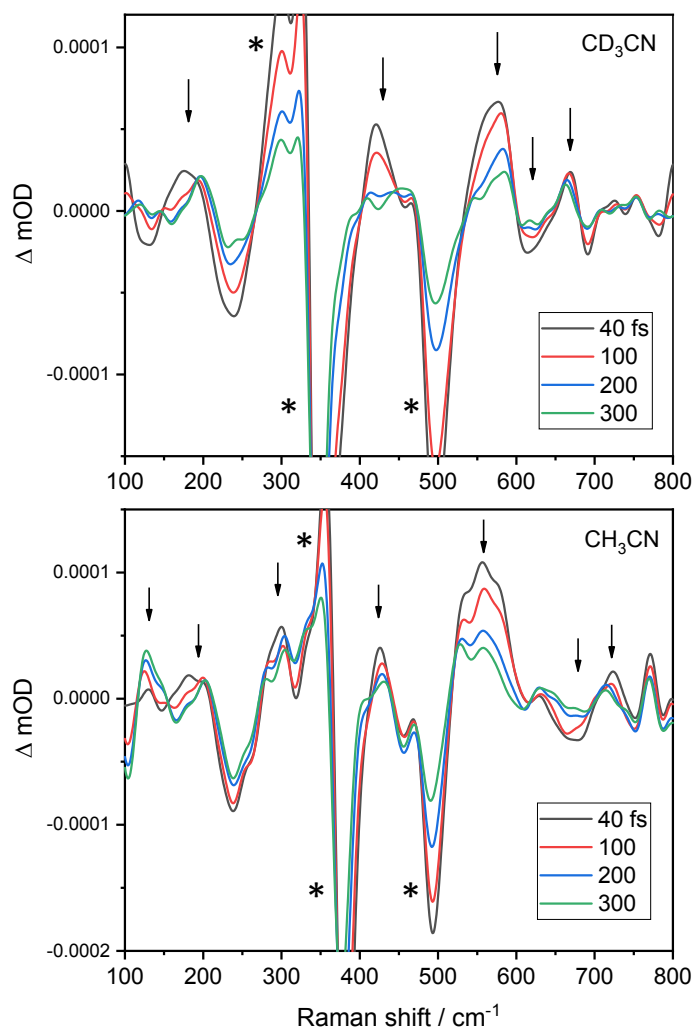

Figure 6. Early FSRS evolution of $\operatorname{ReCl}(\mathrm{CO})_{3}(\mathrm{bpy})$ in $\mathrm{CD}_{3} \mathrm{CN}$ (top) and $\mathrm{CH}_{3} \mathrm{CN}$ (bottom). Spectra are adjusted to a common zero-signal level. * denote incompletely subtracted / shifted solvent bands. The spectra were not corrected for the difference in Raman pump absorption between actinic-pumped and non-actinic pumped FSRS that causes intensity variations of the negative solvent peaks whereas positive excited-state feature are affected much less since the groundstate $\operatorname{ReCl}(\mathrm{CO})_{3}$ (bpy) is several orders of magnitude weaker.

\section{- DISCUSSION}

Ground- and excited-state Raman spectra (FSRS) measured over a full relevant spectral range together with a computational anharmonic vibrational analysis characterize bonding and structural changes upon excitation, while the temporal evolution of the spectra provides information on excited-state relaxation processes that take place on femtosecond to early picosecond timescale. 
Calculations show that most vibrational modes are delocalized over several bonds and molecular fragments (Charts S1, S2). Nevertheless, it is possible to identify groups of vibrations of similar principal contributions (Tables 1, 2). Going up from the lowest energies, these are bpy and ReCO deformations coupled with $\mathrm{Re}-\mathrm{Cl}$ stretches, deformations coupled with $\mathrm{Re}-\mathrm{CO}$ stretches, a group of bpy and Re(bpy) deformations (the latter involving $\operatorname{Re}-\mathrm{N}$ stretching motions), $\mathrm{C}-\mathrm{H}$ deformations, inter-ring $\mathrm{CC}$ stretch coupled with $\mathrm{CC}$ and/or $\mathrm{CN}$ stretches of the bpy ligand, and CC/CN stretching motions of the aromatic rings. $\mathrm{CO}$ vibrations around $2000 \mathrm{~cm}^{-}$ ${ }^{1}$ give rise only to very weak features in the ground-state spectrum. They are entirely absent in the excited-state spectra, presumably due to the lack of resonance enhancement. FSRS peak wavenumbers in the high-frequency range agree with those observed in $\mathrm{TR}^{3}$ spectra of $\operatorname{ReCl}(\mathrm{CO})_{3}(\mathrm{bpy}) \cdot{ }^{26}$ The relative band intensities are, however, different because the $\mathrm{TR}^{3}$ spectra were measured using $400 \mathrm{~nm}$ Raman pump whose proximity to the most intense excited-state electronic absorption band at $373 \mathrm{~nm}$ causes much stronger resonance enhancement than 800 $\mathrm{nm}$ pumping, where the transient absorption is much weaker (Figure S1C, oscillator strengths in the legend). ${ }^{26,51,52}$ Interestingly, excited-state FSRS frequencies and intensity patterns of $\operatorname{ReCl}(\mathrm{CO})_{3}(\mathrm{bpy})$ at $60 \mathrm{ps}$ are very similar to those measured at $100 \mathrm{fs}$ and later for $\left[\mathrm{Ru}(\mathrm{bpy})_{3}\right]^{2+}$ in the $1100-1700 \mathrm{~cm}^{-1}$ range using a virtually identical pump wavelength $(801 \mathrm{~nm}) .{ }^{55}$ The close similarity of excited-state bpy-based Raman features of the complexes with one (Re) and three bpy ligands $(\mathrm{Ru})$ shows that the charge localization at a single bpy in ${ }^{3} \mathrm{MLCT}$-excited $\left[\mathrm{Ru}(\mathrm{bpy})_{3}\right]^{2+}$ occurs in much less than $100 \mathrm{fs}$.

Shifts of Raman features from the ground-state spectrum to the 60 ps spectrum of the relaxed lowest excited state are in agreement with bonding changes expected for the 
$\operatorname{ReCl}(\mathrm{CO})_{3} \rightarrow$ bpy CT character of the lowest excited state: $15,56,57,58,59,60$ The bpy-localized LUMO that becomes singly populated in the excited state is $\pi$-bonding with respect to the inter-ring C$\mathrm{C}$ bond and $\pi$-antibonding toward the ring $\mathrm{CN}$ and $\mathrm{CC}$ bonds (Figure S8). ${ }^{57}$ Accordingly, the predominantly inter-ring $v(\mathrm{CC})$ ground-state mode 58 shifts $\sim 52 \mathrm{~cm}^{-1}$ higher upon excitation (contributing $61 \%$ to the excited-state mode 59, based on the Duschinsky matrix). Modes 60 and 63 , which also have a $v$ (CC-inter-ring) contribution, transform to $60+61$ and 64 , respectively, in the excited state. Each occur ca. $10 \mathrm{~cm}^{-1}$ higher than in the ground state. Bands due to predominantly intra-ring $\mathrm{CC}$ and $\mathrm{CN}$ stretching vibrations shift downwards upon excitation because of a LUMO $\pi^{*}$ character. This is the case of the ground-state mode 66 that amounts to $69 \%$ of the excited state mode 66 , which lies ca. $55 \mathrm{~cm}^{-1}$ lower. Frequencies of the modes with significant $v(\operatorname{Re}-\mathrm{CO})$ contributions, namely 23 and 25 (that remix to form excitedstate modes 21 and 24) decrease on average by $\sim 68 \mathrm{~cm}^{-1}$. The $v(\operatorname{Re}-\mathrm{C})$ downshift is complementary to the upshift of $v(\mathrm{C} \equiv 0)$ vibrations that has been amply demonstrated by TRIR spectroscopy. ${ }^{15,22,23,26}$ Both these effects are caused by decreased $\mathrm{Re} \rightarrow \mathrm{CO} \pi$ back-bonding in the ${ }^{3} \mathrm{MLCT}$ excited state due to depopulation of the Re-CO $\pi$-bonding / $\mathrm{C} \equiv \mathrm{O} \pi$-antibonding HOMO (Figure S8), weakening and strengthening Re- $\mathrm{CO}$ and $\mathrm{C} \equiv \mathrm{O}$ bonds, respectively. Downshifting $v(\mathrm{Re}-\mathrm{CO})$ Raman features upon excitation provides additional evidence for the principal $\operatorname{Re}(\mathrm{CO})_{3} \rightarrow$ bpy contribution to the lowest excited state. It also agrees with the calculated lengthening of axial and equatorial Re-CO bonds when going to the lowest excited state by 0.048 and $0.041 \AA$, respectively. ${ }^{61}$ On the other hand, modes involving the $\mathrm{Re}-\mathrm{Cl}$ stretching motion shift up by ca. $10 \mathrm{~cm}^{-1}$, which is attributable to the depopulation of the Re-Cl $\pi$-antibonding $\operatorname{Re}(\mathrm{d} \pi)$ - $\mathrm{Cl}(\mathrm{p} \pi)$ HOMO (Figure S8). In particular, the $v(\mathrm{ReCl})$-containing ground- 
state modes 14-16 participate in excited-state $v(\mathrm{ReCl})$ modes 15 and 16 that lie, on average lie $10 \mathrm{~cm}^{-1}$ higher. The upshift of $v(\mathrm{ReCl})$ vibrations upon excitation is the third experimental piece of evidence for the $\mathrm{Cl} \rightarrow$ bpy $\mathrm{CT}$ contribution to the excited-state wave function, after the TRIR spectra of $\operatorname{Re}(\mathrm{NCS})(\mathrm{CO})_{3}\left(\right.$ bpy) and time-resolved X-ray absorption of $\operatorname{Re} \operatorname{Br}(\mathrm{CO})_{3}($ bpy $) .{ }^{57,58,59}$

The temporal evolution of the Raman spectra (Figures 4-6, S6) provides insight into the mechanism of the lowest excited-state population and its relaxation. Interestingly, individual Raman bands show different dynamics. High-frequency bands due to bpy-localized CC, CN, and inter-ring C-C stretching vibrations in the $1450-1600 \mathrm{~cm}^{-1}$ range are initially nearly absent (Figure 5). At 40-100 fs, four very weak bands are observed that blue-shift and merge into two broad features between 200 and 300 fs (Figure 5B). Subsequently, they grow with biexponential kinetics ( 0.38 and 21 ps), eventually becoming the strongest features in the $60-p s$ spectrum of the relaxed ${ }^{3} \mathrm{MLCT}$ state. This behavior cannot be attributed to increasing resonance enhancement as the transient absorption at and around the $800 \mathrm{~nm}$ Raman pump is weak and partly decays during the first 2.5 ps (Figure S1). Femtosecond band restructuring was also observed for some of the low-frequency Raman bands, namely in the region of $v(\operatorname{ReCl}) /$ deformation vibrations around $190-200 \mathrm{~cm}^{-1}$, and $\delta(\mathrm{Re}-\mathrm{C}-\mathrm{O})$ bending vibrations around 420-440 and 520-600 $\mathrm{cm}^{-1}$ (Figure 6). This mode-specific dynamics suggests that the electronic wave function (i.e., the excited-state character) changes in the course of relaxation. Initial time evolution in the $1450-1600 \mathrm{~cm}^{-1}$ spectral range agrees with the ultrafast fluorescence decay kinetics $^{52,61}$ whose 85 and 340 fs lifetimes were attributed to the intersystem crossing (ISC) from the optically populated ${ }^{1} \mathrm{MLCT}$ to an intermediate $\pi \pi^{*}$-bpy intraligand ( $\left.{ }^{3} \mathrm{IL}\right)$ and to the lowest ${ }^{3} \mathrm{MLCT}$ excited states, combined with a ${ }^{3} \mathrm{IL} \rightarrow{ }^{3} \mathrm{MLCT}$ conversion. This three-state $\left({ }^{1} \mathrm{MLCT}\right.$, 
$\left.{ }^{3} \mathrm{MLCT},{ }^{3} \mathrm{IL}\right)$ model is a simplification since intersystem crossing actually proceeds through a manifold of intermediate states that arise from spin-orbit splitting of a number of intermediate ${ }^{3} \mathrm{MLCT} /{ }^{3} \mathrm{IL}$ states. ${ }^{50,62,63,64,65,66,67}$ Quantum mechanical simulations of ultrafast excited-state dynamics of $\operatorname{Re}($ halide $)(\mathrm{CO})_{3}(\mathrm{bpy})$ complexes indicate that the initial ISC steps from the optically populated ${ }^{1} \mathrm{MLCT}$ occur in less than $20 \mathrm{fs}$. A more detailed ISC mechanistic picture was obtained by full-dimensional excited-state dynamics simulations of an analogous $\left[\operatorname{Re}(\text { imidazole })(\mathrm{CO})_{3}(1,10-\text { phenanthroline })\right]^{+}$complex, suggesting a two-phase ISC to the lowest triplet state. ${ }^{63}$ In particular, a dynamic equilibrium between triplet and singlet MLCT states is established in less than $10 \mathrm{fs}$ ("prompt ISC"). Then, convoluted intramolecular vibrational energy redistribution (IVR) and internal conversion shifts this equilibrium toward the lowest ${ }^{3}$ MLCT state with a hundreds-of-femtoseconds time constant ("retarded ISC"). The latter process involves a gradually changing excited-state wave function whereby the IL ( $\pi \pi^{*}$-bpy) contribution decreases and the MLCT character increases. ${ }^{63}$ Our FSRS dynamics lends support to this model: The "instantaneous" change of the excited-state wave function is responsible for the presence of most of the excited-state Raman features in a few tens of femtoseconds, whereas the 40-200 fs restructuring of the $v(\mathrm{CC}, \mathrm{CN}) / v(\mathrm{C}-\mathrm{C})_{\text {inter-ring }}$ group of bands and its subsequent $\sim 400 \mathrm{fs}$ growth/upshift are attributable to the "retarded" ISC component. The $v(\mathrm{CC}, \mathrm{CN}) / v(\mathrm{C}-\mathrm{C})_{\text {inter-ring }}$ Raman features in the $1450-1600 \mathrm{~cm}^{-1}$ range are characteristic of the bpy*- ligand and therefore develop and grow in intensity as the excited-state wave function acquires more $\mathrm{ReCl}(\mathrm{CO})_{3} \rightarrow$ bpy $\mathrm{CT}$ character. This process continues well into the picosecond time domain ( $21 \mathrm{ps}$ rise) as the solvational and vibrational relaxation drives the intramolecular charge separation further. These Raman dynamics are consistent with the picosecond growth of 
a bpy ${ }^{\bullet-}$-specific $\sim 380 \mathrm{~nm}$ band in the TA spectra ${ }^{26,52}$ and with the behavior of $v(\mathrm{C} \equiv 0)$ features in TRIR spectra that shift to higher wavenumbers with 1.5 and 12.6 ps time constants and also indicate the presence of another excited state with more ${ }^{3} \mathrm{IL}$ character. ${ }^{26,52,68}$ FSRS dynamics in the low-frequency range mostly concerns features due to vibrational modes that involve $v(\operatorname{Re}-$ $\mathrm{Cl})$ and $\delta(\mathrm{Re}-\mathrm{C}-\mathrm{O})$ motions that were found ${ }^{69}$ to be strongly coupled to the ISC process. In fact, the $40-100 \mathrm{fs}$ spectra show shallow shifting minima at $130-160$ and $\sim 690 \mathrm{~cm}^{-1}$ that develop into weak positive features in few hundreds of femtoseconds. These minima might arise from inverse Raman scattering ${ }^{34}$ due to vibrations that were activated in the course of ISC, as has been predicted theoretically. ${ }^{69}$ Other spectral features exhibit very limited dynamics, usually small picosecond upshifts and growths, generally commensurate with the $\sim 21$ ps growth component identified in the $1450-1600 \mathrm{~cm}^{-1}$ range and mostly attributed to solvational relaxation. Interestingly, the FSRS excited-state dynamics of $\operatorname{ReCl}(C O)_{3}(b p y)$ is more complex than that of $\left[\mathrm{Ru}(\mathrm{bpy})_{3}\right]^{2+}$ that shows $\mathrm{s}^{55}$ a monotonous $\sim 110 \mathrm{fs}$ growth of bpy-- features. The difference is attributable to the time-dependent mixing of $\mathrm{IL}\left(\pi \pi^{*}\right.$-bpy) and $\mathrm{CT}$ characters in the lowest excited state of the rhenium complex, in contrast to a virtually pure MLCT character in the ruthenium case. Furthemore, the low-symmetry and the presence of ligands with different polarities and solvation properties make $\operatorname{ReCl}(\mathrm{CO})_{3}(\mathrm{bpy})$ much more susceptible to solvation dynamics.

\section{- CONCLUSIONS}


Time-resolved FSRS of the lowest excited state of a prototypical organometallic photosensitizer/photocatalyst $\operatorname{ReCl}(\mathrm{CO})_{3}($ bpy $)$ measured from $\sim 40$ to $2000 \mathrm{~cm}^{-1}$ with ca. $40 \mathrm{fs}$ time resolution have demonstrated that:

- Good quality FSRS can be measured in the low-wavenumber region $\left(40-800 \mathrm{~cm}^{-1}\right)$ when the Raman probe continuum is generated with laser pulses of a wavelength $(1400 \mathrm{~nm})$ substantially longer than that of the Raman pump (800 nm). "Watermarking", ${ }^{29}$ whereby a set of spectra measured at 96 slightly different Raman pump wavelengths is used to reconstruct the final spectrum, improves the experiment sensitivity, background rejection, and the $\mathrm{S} / \mathrm{N}$ ratio.

- Anharmonic calculations based on DFT and second-order vibrational perturbation theory provide vibrational frequencies that match the experimental Raman shift wavenumbers with accuracy sufficient to interpret experimental spectra, identify weak features, and with the possibility to predict spectra of electronically excited species and photochemical intermediates. - Shifts of Raman features upon excitation ( $v(\mathrm{ReCl})$ and $v(\mathrm{CC}$-inter-ring) upwards, $v(\mathrm{CC}, \mathrm{CN})$ and $v(\operatorname{Re}-\mathrm{C})$ downwards) agree with the predominant $\operatorname{ReCl}(\mathrm{CO})_{3} \rightarrow$ bpy $\mathrm{CT}$ character of the lowest excited state, demonstrating the diagnostic value of low-frequency Raman modes in excitedstate characterization and the need for reliable assignment provided by anharmonic calculations.

- Temporal evolution of FSRS features is mode-specific and provides information on the dynamics and mechanism of the population of the lowest excited state and its relaxation, namely the development of the charge separation in the relaxed MLCT state. 
FSRS experiments coupled with perturbational anharmonic calculations emerge as a promising tool to investigate the rich excited-state chemistry of Re carbonyl-diimine photosensitizers and photocatalysts.

\section{- AUTHOR INFORMATION}

Corresponding Authors

*E-mail: Miroslav.Kloz@eli-beams.eu

*E-mail: a.vlcek@qmul.ac.uk

\section{ORCID}

Alessandra Picchiotti: 0000-0003-0167-1431

MateuszRebarz: 0000-0002-5823-2432

Nils Lenngren: 0000-0001-7563-9843

Yingliang Liu: 0000-0002-4089-688X

Stanislav Záliš: 0000-0003-4345-3205

Miroslav Kloz: 0000-0003-4609-8018

Antonín Vlček: 0000-0002-6413-8311

\section{Notes}

The authors declare no competing financial interest

\section{- ACKNOWLEDGMENTS}

This work was supported by the Czech Science Foundation (GAČR) grant 17-011375 and EPSRC (UK) grant EP/R029687/1, as well as the Projects ELIBIO (CZ.02.1.01/0.0/0.0/15_003/0000447) and ADONIS (CZ.02.1.01/0.0/0.0/16_019/0000789) from the European Regional Development Fund.

\section{- ASSOCIATED CONTENT}

Supporting Information Available

Transient absorption spectra, ground- and excited-state FSRS in $\mathrm{CH}_{3} \mathrm{CN}$, detailed Duschinsky matrices, time-resolved FSRS in $\mathrm{CD}_{3} \mathrm{CN}$, visualization of selected ground- and excited-state vibrations.

This information is available free of charge via the Internet at https://pubs.acs.org/.

References

1. Vlček, A.; Kvapilová, H.; Towrie, M.; Záliš, S., Electron-Transfer Acceleration Investigated by Time Resolved Infrared Spectroscopy. Acc. Chem. Res. 2015, 48, 868-876. 
2. Dereka, B.; Koch, M.; Vauthey, E., Looking at Photoinduced Charge Transfer Processes in the IR: Answers to Several Long-Standing Questions. Acc. Chem. Res. 2017, 50, 426-434.

3. Kukura, P.; Yoon, S.; Mathies, R. A., Femtosecond Stimulated Raman Spectroscopy. Anal. Chem. 2006, 78, 5952-5959.

4. Frontiera, R. R.; Mathies, R. A., Femtosecond Stimulated Raman Spectroscopy. Laser Photonics Rev. 2011, 5 .

5. Brown, K. E.; Veldkamp, B. S.; Co, D. T.; Wasielewski, M. R., Vibrational Dynamics of a Perylene-Perylenediimide Donor-Acceptor Dyad Probed with Femtosecond Stimulated Raman Spectroscopy. J. Phys. Chem. Lett. 2012 3,2362-2366.

6. Dietze, D. R.; Mathies, R. A., Femtosecond Stimulated Raman Spectroscopy. ChemPhysChem 2016, 17, 1224-1251.

7. Hoffman, D. P.; Mathies, R. A., Femtosecond Stimulated Raman Exposes the Role of Vibrational Coherence in Condensed-Phase Photoreactivity. Acc. Chem. Res. 2016, 49, 616-625.

8. Ghosh, A.; Ostrander, J. S.; Zanni, M. T., Watching Proteins Wiggle: Mapping Structures with TwoDimensional Infrared Spectroscopy. Chem. Rev. 2017, 117, 10726-10759.

9. Lima, M.; Candelaresi, M.; Foggia, P., 2D-IR Spectroscopy: An Additional Dimension to Investigate Ultrafast Structural Dynamics. J. Raman Spectrosc. 2013, 44, 1470-1477.

10. Latouche, C.; Palazzetti, F.; Skouteris, D.; Barone, V., High-Accuracy Vibrational Computations for Transition-Metal Complexes Including Anharmonic Corrections: Ferrocene, Ruthenocene, and Osmocene as Test Cases. J. Chem. Theory Comput. 2014, 10, 4565-4573.

11. Barone, V.; Biczysko, M.; Bloino, J., Fully Anharmonic IR and Raman Spectra of Medium-Size Molecular Systems: Accuracy and Interpretation. Phys. Chem. Chem. Phys. 2014, 16, 1759-1787.

12. Meinnel, J.; Latouche, C.; Ghanemi, S.; Boucekkine, A.; Barone, V.; Moréac, A.; Boudjada, A., Anharmonic Computations Meet Experiments (IR, Raman, Neutron Diffraction) for Explaining the Behavior of 1,3,5-Tribromo-2,4,6-trimethylbenzene. J. Phys. Chem. A 2016, 120, 1127-1132.

13. Bloino, J.; Biczysko, M., IR and Raman Spectroscopies beyond the Harmonic Approximation: The Second-Order Vibrational Perturbation Theory Formulation. Reference Module in Chemistry, Molecular Sciences and Chemical Engineering, Elsevier: 2015.

14. Kvapilová, H.; Vlček, A., Jr.; Barone, V.; Biczysko, M.; Záliš, S., Anharmonicity Effects in IR Spectra of $\left[\operatorname{Re}(\mathrm{X})(\mathrm{CO})_{3}\left(\alpha\right.\right.$-diimine)] ( $\alpha$-diimine $=2,2^{\prime}$-bipyridine or pyridylimidazo[1,5-a]pyridine; $\mathrm{X}=\mathrm{Cl}$ or NCS) Complexes in Ground and Excited Electronic States. J. Phys. Chem. A 2015, 119, 10137-10146.

15. Vlček, A., Jr., Ultrafast Excited-State Processes in Re(I) Carbonyl-Diimine Complexes: From Excitation to Photochemistry. Top. Organomet. Chem. 2010, 29, 73-114.

16. Kumar, A.; Sun, S.-S.; Lees, A. J., Photophysics and Photochemistry of Organometallic Rhenium Diimine Complexes. Top. Organomet. Chem. 2010, 29, 1-35.

17. Lee, L. C.-C.; Leung, K.-K.; Lo, K. K.-W., Recent Development of Luminescent Rhenium(I) Tricarbonyl Polypyridine Complexes as Cellular Imaging Reagents, Anticancer Drugs, and Antibacterial Agents. Dalton Trans. 2017, 46, 16357-16380.

18. Hawecker, J.; Lehn, J.-M.; Ziessel, R., Efficient Photochemical Reduction of $\mathrm{CO}_{2}$ to $\mathrm{CO}$ by Visible Light Irradiation of Systems Containing $\operatorname{Re}(\mathrm{X})(\mathrm{CO})_{3}(\mathrm{bpy})$ or $\mathrm{Ru}(\mathrm{bpy})_{3}{ }^{2+}-\mathrm{Co}^{2+}$ Combination as Homogeneous Calysts. J. Chem. Soc., Chem. Commun. 1983, 536-538.

19. Hawecker, J.; Lehn, J.-M.; Ziessel, R., Electrocatalytic Reduction of Carbon Dioxide Mediated by $\operatorname{Re}($ bipy $)(\mathrm{CO})_{3} \mathrm{Cl}$ (bipy = 2,2'-bipyridine). J. Chem. Soc., Chem. Commun. 1984, 328-330.

20. Hawecker, J.; Lehn, J.-M.; Ziessel, R., Photochemical and Electrochemical Reduction of $\mathrm{CO}_{2}$ to $\mathrm{CO}$ Mediated by $\operatorname{Re}(\mathrm{Cl})(\mathrm{CO})_{3}$ (bpy) and Related Complexes as Homogeneous Catalysts. Helv. Chim. Acta 1986, 69, 1990-2009. 
21. Takeda, H.; Ishitani, O., Development of Efficient Photocatalytic Systems for $\mathrm{CO}_{2}$ Reduction Using Mononuclear and Multinuclear Metal Complexes Based on Mechanistic Studies. Coord. Chem. Rev. 2010, 254, 346-354.

22. George, M. W.; Johnson, F. P. A.; Westwell, J. R.; Hodges, P. M.; Turner, J. J., Excited -state Properties and Reactivity of $\left[\operatorname{Re}(\mathrm{Cl})(\mathrm{CO})_{3}(\mathrm{bpy})\right]$ Studied by Time-Resolved Infrared Spectroscopy. J. Chem. Soc., Dalton Trans. 1993, 2977-2979.

23. Dattelbaum, D. M.; Omberg, K. M.; Hay, P. J.; Gebhart, N. L.; Martin, R. L.; Schoonover, J. R.; Meyer, T. J., Defining Electronic Excited States Using Time-Resolved Infrared Spectroscopy and Density Functional Theory Calculations. J. Phys. Chem. A 2004, 108, 3527-3536.

24. Blanco-Rodríguez, A. M.; Towrie, M.; Sýkora, J.; Záliš, S.; Vlček, A., Jr., Photoinduced Intramolecular Tryptophan Oxidation and Excited-State Behavior of $\left[\operatorname{Re}^{\prime}(\mathrm{L}-\mathrm{AA})(\mathrm{CO})_{3}(\text { diimine })\right]^{+}(\mathrm{L}=$ pyridine or imidazole, AA = tryptophan, tyrosine, phenylalanine) Inorg. Chem. 2011, 50, 6122-6134.

25. Blanco-Rodríguez, A. M.; Ronayne, K. L.; Záliš, S.; Sýkora, J.; Hof, M.; Vlček, A., Jr., Solvation-Driven Excited-State Dynamics of $\left[\operatorname{Re}(4-E t-p y r i d i n e)(\mathrm{CO})_{3}\left(2,2^{\prime} \text {-bipyridine }\right)\right]^{+}$in Imidazolium lonic Liquids. A TimeResolved Infrared and Phosphorescence Study. J. Phys. Chem. A 2008, 112, 3506-3514.

26. Liard, D. J.; Busby, M.; Matousek, P.; Towrie, M.; Vlček, A., Jr., Picosecond Relaxation of ${ }^{3}$ MLCT Excited States of $\left[\operatorname{Re}(\operatorname{Etpy})(\mathrm{CO})_{3}(\mathrm{dmb})\right]^{+}$and $\left[\operatorname{Re}(\mathrm{Cl})(\mathrm{CO})_{3}(\mathrm{bpy})\right]$ as Revealed by Time-Resolved Resonance Raman, IR and UV-Vis Absorption Spectroscopy. J. Phys. Chem. A 2004, 108, 2363-2369.

27. Smothers, W. K.; Wrighton, M. S., Raman Spectroscopy of the Ground and MLCT Excited $\operatorname{Re}(\mathrm{Cl})(\mathrm{CO})_{3}(\mathrm{bpy})$ and $\mathrm{Ru}(\mathrm{bpy})_{3}$. J. Am. Chem. Soc. 1983, 105, 1067-1069.

28. Worl, L. A.; Duesing, R.; Chen, P.; Della Ciana, L.; Meyer, T. J., Photophysical Properties of $\operatorname{Re}(\mathrm{Cl})(\mathrm{CO})_{3}\left(\mathrm{X}_{2}\right.$-bpy). J. Chem. Soc. Dalton Trans. 1991, 849-858.

29. Kloz, M.; Weissenborn, J.; Polívka, T.; Frank, H. A.; Kennis, J. T. M., Spectral Watermarking in Femtosecond Stimulated Raman Spectroscopy: Resolving the Nature of the Carotenoid S* State. Phys. Chem. Chem. Phys. 2016, 18, 14619-14628.

30. McCamant, D. W.; Kukura, P.; Yoon, S.; Mathies, R. A., Femtosecond Broadband Stimulated Raman Spectroscopy: Apparatus and Methods. Rev. Sci. Instrum. 2004, 75, 4971-4980.

31. Laimgruber, S.; Schachenmayr, H.; Schmidt, B.; Zinth, W.; Gilch, P., A Femtosecond Stimulated Raman Spectrograph for the Near Ultraviolet. Appl. Phys. B-Lasers Opt. 2006, 85, 557-564

32. Brunsgaard-Hansen, S.; Berg, R. W.; Stenby, E. H., Upgrade of a Raman Spectrometer. Appl. Spectrosc. Rev. 2004, 39, 385-397.

33. Oscar, B. G.; Chen, C.; Liu, W.; Zhu, L.; Fang, C., Dynamic Raman Line Shapes on an Evolving ExcitedState Landscape: Insights from Tunable Femtosecond Stimulated Raman Spectroscopy. J. Phys. Chem. A 2017, 121, 5428-5441.

34. Weigel, A.; Ernsting, N. P., Excited Stilbene: Intramolecular Vibrational Redistribution and Solvation Studied by Femtosecond Stimulated Raman Spectroscopy. J. Phys. Chem. B 2010, 114, 7879-7893.

35. Kloz, M.; van Grondelle, R.; Kennis, J. T. M., Wavelength-Modulated Femtosecond Stimulated Raman Spectroscopy - Approach Towards Automatic Data Processing. Phys. Chem. Chem. Phys. 2011, 13, 1812318133.

36. Wende, T.; Liebel, M.; Schnedermann, C.; Pethick, R. J.; Kukura, P., Population-Controlled Impulsive Vibrational Spectroscopy: Background- and Baseline-Free Raman Spectroscopy of Excited Electronic States. J. Phys. Chem. A 2014, 118, 9976-9984.

37. Kuramochi, H.; Takeuchi, S.; Kamikubo, H.; Kataoka, M.; Tahara, T., Fifth-Order Time-Domain Raman Spectroscopy of Photoactive Yellow Protein for Visualizing Vibrational Coupling in its Excited State. Sci. Adv. 2019, 5, eaau4490.

38. Frisch, M. J.; Trucks, G. W.; Schlegel, H. B.; Scuseria, G. E.; Robb, M. A.; Cheeseman, J. R.; Scalmani, G.; Barone, V.; Petersson, G. A.; Nakatsuji, H.; et al. Gaussian16, Revision A.03, Gaussian, Inc.: Wallingford, CT, 2016. 
39. Becke, A. D., Density-Functional Thermochemistry. III. The Role of Exact Exchange. J. Chem. Phys. 1993, 98, 5648-5652.

40. Lee, C.; Yang, W.; Parr, R. G., Development of the Colic-Salvetti Correlation-Energy Formula into a Functional of the Electron Density. Phys. Rev. B 1988, 37, 785-789.

41. Andrae, D.; Häussermann, U.; Dolg, M.; Stoll, H.; Preuss, H., Energy-Adjusted ab initio Pseudopotentials for the Second and Third Row Transition Elements. Theor. Chim. Acta 1990, 77, 123141.

42. Martin, J. M. L.; Sundermann, A., Correlation Consistent Valence Basis Sets for Use with the Stuttgart-Dresden-Bonn Relativistic Effective Core Potentials: The Atoms Ga-Kr and In-Xe. J. Chem. Phys. 2001, 114, 3408-3420.

43. Krishnan, R.; Binkley, J. S.; Seeger, R.; Pople, J. A., Self-Consistent Molecular Orbital Methods. XX. A Basis Set for Correlated Wave Functions. J. Chem. Phys. 1980, 72, 650-654.

44. Cossi, M.; Rega, N.; Scalmani, G.; Barone, V., Energies, Structures, and Electronic Properties of Molecules in Solution with the C-PCM Solvation Model. J. Comput. Chem. 2003, 24, 669-681.

45. Barone, V.; Bloino, J.; Guido, C. A.; Lipparini, F., A Fully Automated Implementation of VPT2 Infrared Intensities. Chem. Phys. Lett. 2010, 496, 157-161.

46. Barone, V.; Biczysko, M.; Bloino, J.; Borkowska-Panek, M.; Carnimeo, I.; Panek, P., Toward Anharmonic Computations of Vibrational Spectra for Large Molecular Systems. Int. J. Quantum Chem. 2012, 112, 2185-2200.

47. Bloino, J.; Biczysko, M.; Barone, V., Anharmonic Effects on Vibrational Spectra Intensities: Infrared, Raman, Vibrational Circular Dichroism, and Raman Optical Activity. J. Phys. Chem. A 2015, 119, 1186211874.

48. Piccardo, M.; Bloino, J.; Barone, V., Generalized Vibrational Perturbation Theory for Rotovibrational Energies of Linear, Symmetric and Asymmetric Tops: Theory, Approximations, and Automated Approaches to Deal with Medium-to-Large Molecular Systems. Int. J. Quantum Chem. 2015, 115, 948982.

49. Licari, D.; Baiardi, A.; Biczysko, M.; Egidi, F.; Latouche, C.; Barone, V., Implementation of a Graphical User Interface for the Virtual Multifrequency Spectrometer: The VMS-Draw Tool. J. Comput. Chem. 2015, 36, 321-334.

50. Heydová, R.; Gindensperger, E.; Romano, R.; Sýkora, J.; Vlček, A., Jr.; Záliš, S.; Daniel, C., Spin-Orbit treatment of UV-vis Absorption Spectra and Photophysics of Rhenium(I) Carbonyl-Bipyridine Complexes: MS-CASPT2 and TD-DFT Analysis. J. Phys. Chem. A 2012, 116, 11319-11329.

51. Záliš, S.; Consani, C.; El Nahhas, A.; Cannizzo, A.; Chergui, M.; Hartl, F.; Vlček, A., Jr., Origin of Electronic Absorption Spectra of MLCT-Excited and One-Electron Reduced 2,2'-bipyridine and 1,10phenanthroline Complexes. Inorg. Chim. Acta 2011, 374, 578-585.

52. El Nahhas, A.; Cannizzo, A.; van Mourik, F.; Blanco-Rodríguez, A. M.; Záliš, S.; Vlček, A., Jr.; Chergui, M., Ultrafast Excited-State Dynamics of $\left[\operatorname{Re}(\mathrm{L})(\mathrm{CO})_{3}(\mathrm{bpy})\right]^{\text {n }}$ Complexes: Involvement of the Solvent $J$. Phys. Chem. A 2010, 114, 6361-6369.

53. Kiefer, L. M.; King, J. T.; Kubarych, K. J., Equilibrium Excited State Dynamics of a Photo-Activated Catalyst Measured with Ultrafast Transient 2DIR. J. Phys. Chem. A 2014, 118, 9853-9860.

54. Kiefer, L. M.; King, J. T.; Kubarych, K. J., Dynamics of Rhenium Photocatalysts Revealed through Ultrafast Multidimensional Spectroscopy. Acc. Chem. Res. 2015, 48, 1123-1130.

55. Yoon, S.; Kukura, P.; Stuart, C. M.; Mathies, R. A., Direct Observation of the Ultrafast Intersystem Crossing in Tris(2,2'-bipyridine)ruthenium(II) using Femtosecond Stimulated Raman Spectroscopy. Mol. Phys. 2006, 104, 1275-1282.

56. Stufkens, D. J.; Vlček, A., Jr., Ligand-Dependent Excited State Behaviour of Re(I) and Ru(II) CarbonylDiimine Complexes. Coord. Chem. Rev. 1998, 177, 127-179. 
57. Blanco-Rodríguez, A. M.; Gabrielsson, A.; Motevalli, M.; Matousek, P.; Towrie, M.; Šebera, J.; Zálišs, S.; Vlček, A., Jr., Ligand-to-Diimine / Metal-to-Diimine Charge-Transfer Excited States of $\left[\operatorname{Re}(\mathrm{NCS})(\mathrm{CO})_{3}(\alpha-\right.$ diimine)] ( $\alpha$-diimine $=2,2^{\prime}$-bipyridine, di-iPr-N,N-1,4-diazabutadiene). A Spectroscopic and Computational Study. J. Phys. Chem. A 2005, 109, 5016-5025.

58. El Nahhas, A.; van der Veen, R. M.; Penfold, T. J.; Pham, V.-T.; Lima, F. A.; Abela, R.; BlancoRodríguez, A. M.; Záliš, S.; Vlček, A., Jr.; Tavernelli, I.; Rothlisberger, U.; Milne, C. J.; Chergui, M., X-Ray Absorption Spectroscopy of Ground and Excited Rhenium-Carbonyl-Diimine Complexes: Evidence for a Two-Centre Electron Transfer. J. Phys. Chem. A 2013, 117, 361-369.

59. Záliš, S.; Milne, C. J.; El Nahhas, A.; Blanco-Rodriguez, A. M.; van der Veen, R. M.; Vlček, A., Jr., Re and $\mathrm{Br}$ X-ray Absorption Near Edge Structure Study of the Ground and Excited States of $\left[\operatorname{ReBr}(\mathrm{CO})_{3}(\mathrm{bpy})\right]$ Interpreted by DFT and TD-DFT Calculations. Inorg. Chem. 2013, 52, 5775-5785.

60. Mai, S.; Plasser, F.; Dorn, J.; Fumanal, M.; Daniel, C.; González, L., Quantitative Wave Function Analysis for Excited States of Transition Metal Complexes. Coord. Chem. Rev. 2018, 361, 74-97.

61. Cannizzo, A.; Blanco-Rodríguez, A. M.; Nahhas, A.; Šebera, J.; Záliš, S.; Vlček, A., Jr.; Chergui, M., Femtosecond Fluorescence and Intersystem Crossing in Rhenium(I) Carbonyl-Bipyridine Complexes $J$. Am. Chem. Soc. 2008, 130, 8967-8974.

62. Baková, R.; Chergui, M.; Daniel, C.; Vlček, A., Jr.; Záliš, S., Relativistic Effects in Spectroscopy and Photophysics of Heavy-Metal Complexes Illustrated by Spin-Orbit Calculations of [Re(imidazole)(CO) $)_{3}$ (phen)] ${ }^{+}$. Coord. Chem. Rev. 2011, 255, 975-989.

63. Mai, S.; González, L., Unconventional Two-Step Spin Relaxation Dynamics of $\left[\operatorname{Re}(\mathrm{CO})_{3}(\mathrm{im})(\mathrm{phen})\right]^{+}$in Aqueous Solution. Chem. Sci. 2019, 10, 10405-10411.

64. Mai, S.; Gattuso, H.; Fumanal, M.; Muñoz-Losa, A.; Monari, A.; Daniel, C.; González, L.; Webb, S. E. D., Excited States of a Rhenium Carbonyl Diimine Complex: Solvation Models, Spin-Orbit Coupling, and Vibrational Sampling Effects. Phys. Chem. Chem. Phys. 2017, 19, 27240-27250.

65. Fumanal, M.; Gindensperger, E.; Daniel, C., Ultrafast Excited-State Decays in $\left[\operatorname{Re}(\mathrm{CO})_{3}(\mathrm{~N}, \mathrm{~N})(\mathrm{L})\right]^{\mathrm{n}+}$ : Nonadiabatic Quantum Dynamics. J. Chem. Theory Comput. 2017, 13, 1293-1306.

66. Gourlaouen, C.; Eng, J.; Otsuka, M.; Gindensperger, E.; Daniel, C., Quantum Chemical Interpretation of Ultrafast Luminescence Decay and Intersystem Crossings in Rhenium(I) Carbonyl Bipyridine Complexes. J. Chem. Theory Comput. 2015, 11, 99-110.

67. Eng, J.; Gourlaouen, C.; Gindensperger, E.; Daniel, C., Spin-Vibronic Quantum Dynamics for Ultrafast Excited-State Processes. Acc. Chem. Res. 2015, 48, 809-817.

68. El Nahhas, A.; Consani, C.; Blanco-Rodríguez, A. M.; Lancaster, K. M.; Braem, O.; Cannizzo, A.; Towrie, M.; Clark, I. P.; Zálišs, S.; Chergui, M.; Vlček, A., Jr., Ultrafast Excited-State Dynamics of Rhenium(I) Photosensitizers $\left[\operatorname{Re}(\mathrm{Cl})(\mathrm{CO})_{3}(\mathrm{~N}, \mathrm{~N})\right]$ and $\left[\operatorname{Re}(\text { imidazole })(\mathrm{CO})_{3}(\mathrm{~N}, \mathrm{~N})\right]^{+}$: Diimine Effects. Inorg. Chem. 2011, 50, 2932-2943.

69. Harabuchi, Y.; Eng, J.; Gindensperger, E.; Taketsugu, T.; Maeda, S.; Daniel, C., Exploring the Mechanism of Ultrafast Intersystem Crossing in Rhenium(I) Carbonyl Bipyridine Halide Complexes: Key Vibrational Modes and Spin-Vibronic Quantum Dynamics. J. Chem. Theory Comput. 2016, 12, 2335-2345. 


\section{Table of contents graphics}

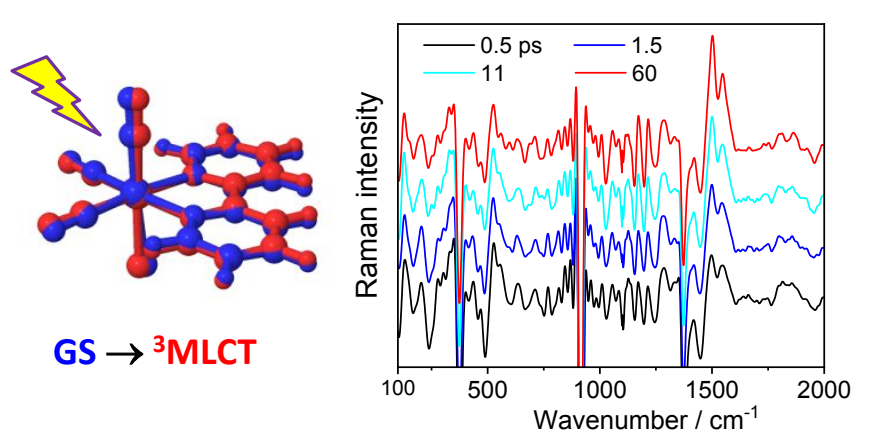

